\title{
¿Optimal Spectral Nudging for Global Dynamic Downscaling
}

\author{
MARTina Schubert-Frisius, Frauke Feser, AND HANS vOn STORCH \\ Institute for Coastal Research, Helmholtz Centre Geesthacht, Geesthacht, Germany \\ SEBASTIAN RAST \\ Max Planck Institute for Meteorology, Hamburg, Germany
}

(Manuscript received 23 January 2016, in final form 10 September 2016)

\begin{abstract}
This study analyzes a method of constructing a homogeneous, high-resolution global atmospheric hindcast. The method is the spectral nudging technique, which was applied to a state-of-the-art general circulation model (ECHAM6, T255L95). Large spatial scales of the global climate model prognostic variables were spectrally nudged toward a reanalysis dataset (NCEP-1, T62L28) for the past few decades. The main idea is the addition of dynamically consistent regional weather details to the coarse-grid NCEP-1 reanalysis. A large number of sensitivity experiments was performed, using different nudging $e$-folding times, vertical profiles, wavenumbers, and variables. Comparisons with observations and several reanalyses showed a high dependency on the variations of the nudging configuration. At the global scale, the accordance is very high for extratropical regions and lower in the tropics. A wavenumber truncation of 30, a relatively short $e$-folding time of $50 \mathrm{~min}$, and a plateaushaped nudging profile applied only to divergence and vorticity generally yielded the best results. This is one of the first global spectral nudging hindcast studies and the first applying an altitude-dependent profile to selected prognostic variables. The method can be applied to reconstructing the history of extreme events such as intense storms within the context of ongoing climate change.
\end{abstract}

\section{Introduction}

Reanalysis data play an important role in assessing climate statistics and evaluating global and regional climate models. Great efforts are being undertaken to improve the combination of data assimilation and numerical weather prediction to record the most realistic state of the atmosphere at all scales. Producing this kind of data is very time consuming and cost intensive. Recently, reanalysis data became available at high resolutions; however, most datasets covering a longer time period are at resolutions of about $200 \mathrm{~km}$. An economic and effective approach to produce a "poor man's" reanalysis at the regional scale is the spectral nudging method, first introduced by Waldron et al. (1996) for limited area models and later extended by von Storch et al. (2000) for applications in a regional climate model

¿ Denotes content that is immediately available upon publication as open access.

Corresponding author e-mail: Martina Schubert-Frisius, martina.schubert-frisius@hzg.de
(RCM). For certain weather situations, the RCM tends to deviate from the observed state as a result of internal model variability. The spectral nudging technique "nudges" the large spatial scales of the RCM toward the large scales of the reanalysis data in order to reduce these deviations and to achieve an atmospheric state close to the observed one. The idea behind this is that the reanalysis is well resolved at the global spatial scale and therefore should be close to the RCM results at these scales. This is not the case for the regional scales, as these are only resolved in the RCM and therefore spectral nudging is not applied for small-scale weather systems. The nudging technique is generally not applied to near-surface model levels where most of the regional processes take place (i.e., because of orographic features and land-sea contrast). Within the past few years many spectral nudging sensitivity studies were performed within the context of nested regional models that analyzed the effects of the choice of vertical nudging profiles, nudging strength, wavenumber truncation, varying domain sizes, and meteorological variables (Riette and Caya 2002; Miguez-Macho et al. 2004; Miguez-Macho et al. 2005; Radu et al. 2008; Alexandru et al. 2009). A major problem is the determination of an 
optimal $e$-folding time. If the $e$-folding time is too short, the model results will be dominated by the forcing and it is possible that dynamical imbalances in the observations will be spuriously amplified. On the other hand, a long $e$-folding time could have the effect that the influence of the observations is not large enough. Recently, the spectral nudging method was successfully applied by Yoshimura and Kanamitsu (2008) in a high-resolution atmospheric general circulation model (GCM) at a resolution of T248L28, which corresponds to a gridpoint distance of about $50 \mathrm{~km}$ on the quadratic transform grid. Yoshimura and Kanamitsu used the National Centers for Environmental Prediction NCEP-2 reanalysis dataset as forcing for the year 2001. Kim and Hong (2012) performed a 31-yr global hindcast simulation (1979-2011) by using the same nudging technique and forcing data in a GCM with a lower horizontal and vertical resolution (T126L28) with a spatial resolution of about $100 \mathrm{~km}$ in the gridpoint distance. Kim and Hong used a modified spectral nudging technique where all prognostic variables for selected zonal wavenumbers were nudged height independently. A preservation of zonally averaged temperature and moisture fields was enforced. These studies showed that an improvement of the daily variability of precipitation and a correction of the inherent biases in the reanalysis can be achieved using more realistic model physics.

In a first global nudging sensitivity study, Jeuken et al. (1996) adapted the global European Centre for MediumRange Weather Forecasts (ECMWF) analyses in a threedimensional dynamical upscaling process to force the atmospheric GCM ECHAM3 at low resolution (T21L19). However, the nudging configuration was modified to optimize the transport of dust and sea salt in ECHAM4 (T42L19) (Timmreck and Schulz 2004). In another sensitivity study for the global models CAM5 $\left(1.9^{\circ}\right.$ latitude $\times$ $2.5^{\circ}$ longitude with 30 vertical layers) and ECHAM6HAM2 (T63L31), Zhang et al. (2014) suggested a windonly nudging approach to studying the aerosol indirect effects. Matthias et al. (2015) used the nudged version of CMAM to study meteorological quantities in the middle atmosphere up to $100 \mathrm{~km}$. In addition to the studies of Yoshimura and Kanamitsu (2008) and Kim and Hong (2012), only Scinocca et al. (2016) have applied the spectral nudging technique in a GCM (CanESM2 at T63L35) so far. A height-independent nudging profile with a relaxation time of $24 \mathrm{~h}$ for wind, temperature, and specific humidity was taken to force the model fields toward the ERAInterim truncated at T21. The newly generated dataset in turn drives a regional model that employs exactly the same physics package. This new approach may represent a promising method for downscaling climate predictions.

In the present study we use ECHAM6 at high resolution (T255L95) to analyze the sensitivity of spectral nudging to various parameters. We largely extended the work of Jeuken et al. (1996) and Zhang et al. (2014) by adding various height profiles and by adding the possibility to nudge selectively the various wavenumbers. We assess the quality of each nudging configuration for a global dynamical downscaling with ECHAM6.

As the model system is not changing over time, it can be used to produce a long-term high-resolution climate reconstruction. Global regionalizations of this kind are especially valuable for meso- and small-scale features that are not represented in coarser long-term reanalysis products. For instance, the path and strength of hurricanes, medicanes, and extratropical storms; precipitation patterns over complex structured terrain; or regional temperature and precipitation features can be simulated realistically in the hindcast. This also applies to extreme events such as heat waves or hydrological events related to floods and droughts. Such a long-term hindcast could provide more robust conclusions related to climate variability.

This paper is organized as follows. In section 2 we give a brief description of the global spectral model ECHAM6 and a theoretical overview of the global spectral nudging technique. The design of the sensitivity experiments is presented in section 3 . In section 4, results of the experiments performed are shown and compared with various datasets. Finally, the summary and conclusions are given in section 5 .

\section{Model and spectral nudging technique}

\section{a. ЕСHAM6}

In this study, we use the sixth generation of the general circulation model ECHAM, version ECHAM-6.1.00 (Giorgetta et al. 2013b), as it was used for the CMIP5 model intercomparison project (Giorgetta et al. 2013a). Originally, this model was based on the numerical weather model of the ECMWF but contains many modifications for a better adaptation to climate research. We do not couple the model to an ocean model, as was done for the CMIP5 simulations, but prescribe monthly averaged sea surface temperature (SST) and sea ice coverage as given by the NCEPNCAR (Kalnay et al. 1996) reanalysis dataset. This ensures that the lower boundary conditions are compatible with the nudging data that will be used to force near-realistic largescale dynamics in the model. Furthermore, a land and vegetation model is coupled to the GCM. ECHAM6 is a spectral model that uses an expansion in spherical harmonics of logarithm of the surface pressure, atmospheric temperature, divergence, and vorticity in its dynamical core, namely

$$
X(\lambda, \mu, \eta, t)=\sum_{m=-M}^{M} \sum_{n=|m|}^{N(M)} X_{n}^{m}(\eta, t) P_{n}^{m}(\mu) e^{\mathrm{im} \lambda},
$$


where $X$ denotes a prognostic variable as a function of longitude $\lambda$, sine of latitude $\mu$, vertical coordinate $\eta$, and the time $t ; m$ denotes the zonal wavenumber; and $n$ the total wavenumber. To get a triangular truncation in the wavenumber space, the condition $N=M$ has to be fulfilled. The $P_{n}^{m}$ s are the associated Legendre functions of the first kind. In addition to the spectrally represented variables, specific humidity, cloud water, and cloud ice are time integrated only in gridpoint space.

ECHAM6 was run at the low-resolution (LR) T63L47 spectral resolution for the CMIP5 initiative, but we use the extra-high-resolution (XR) T255L95 for our downscaling experiments. The T255 resolution means a triangular truncation at total wavenumber 255 and a quadratic transform grid with a grid distance of $50 \mathrm{~km}$ at the equator. The L95 vertical resolution uses 95 hybrid terrainfollowing coordinates up to an altitude of $0.01 \mathrm{hPa}$, which corresponds to a height of about $80 \mathrm{~km}$ above the sea surface. The semi-implicit time integration scheme has a time step of $120 \mathrm{~s}$.

\section{b. The spectral nudging technique}

Spectral nudging minimizes deviations of a weather or climate model using a reference reanalysis or observation dataset at selected large spatial scales. These scales normally encompass large weather phenomena, which are well resolved in the forcing data, such as Rossby waves, large pressure systems, or trade winds. This may also include smaller weather systems, if the reanalysis features higher resolution. These scales should not be altered by the RCM or GCM since they are already well resolved in the forcing reanalysis or other reference datasets. In the following we will describe the application of spectral nudging for a GCM. The large-scale dynamic state produced by ECHAM6 at time $t$ on a sigma-hybrid level $\eta$ can be represented by the complexvalued amplitude $X(\eta, t)$ for each spectral coefficient of a meteorological variable to be nudged. The spectral nudging technique consists of adding an additional relaxation term to the prognostic equations for the spectral coefficients. These equations take the following form in spectral space:

$\frac{\partial X_{n}^{m}(\eta, t)}{\partial t}=F_{n}^{m}(\eta, t)+G_{n}^{m}(\eta)\left[X_{n}^{m(\text { reana })}(\eta, t)-X_{n}^{m}(\eta, t)\right]$,

where $F_{n}^{m}(\eta, t)$ denotes the model forcing including all physical and dynamical processes, $X_{n}^{m \text { (reana) }}(\eta, t)$ the driving data given by the NCEP- 1 reanalysis, and $G_{n}^{m}(\eta)$ the nudging coefficient.

For the time integration of Eq. (2), the nudging is performed in two steps. First, the model forcing $F_{n}^{m}(\eta, t)$ is calculated, yielding a new value for the prognostic variable $X_{n}^{m^{*}}(\eta, t+\Delta t)$ in the pre-nudging process:

$$
X_{n}^{m^{*}}(\eta, t+\Delta t)=X_{n t}^{m}(\eta, t)+F_{n}^{m}(\eta, t) \Delta t .
$$

In a second implicit time step, the nudging procedure will be performed by adding the relaxation term $G_{n}^{m}(\eta)\left[X_{n}^{m(\text { reana) }}(\eta, t+\Delta t)-X_{n}^{m}(\eta, t+\Delta t)\right]$ :

$$
\begin{aligned}
X_{n}^{m}(\eta, t+\Delta t)= & X_{n}^{m^{*}}(\eta, t+\Delta t) \\
& +\frac{G_{n}^{m}(\eta) \Delta t}{1+G_{n}^{m}(\eta) \Delta t}\left[X_{n}^{m(\text { reana })}(\eta, t+\Delta t)\right. \\
& \left.-X_{n}^{m^{*}}(\eta, t+\Delta t)\right]
\end{aligned}
$$

which results in the new value $X_{n}^{m}(\eta, t+\Delta t)$. In the following, we suppress the indices for zonal wavenumber $m$ and total wavenumber $n$ if the same values of these quantities are applied to all specified wavenumbers. In the relaxation term, we define $\tau(\eta):=1 / G(\eta)$ as the nudging $e$-folding time.

\section{c. Preprocessing of the NCEP-1 reanalysis data}

For our study we used 6-hourly NCEP-1 reanalysis data, from 1948 to the present day. Our approach uses a Gaussian grid of $192 \times 96$ grid points, being equivalent to a gridpoint distance of about $210 \mathrm{~km}$ at the equator. NCEP-1 reanalysis data are provided in gridpoint space at a resolution that corresponds to the T62L28 spectral resolution on terrain-following sigma-hybrid levels, whereas a spectral resolution of T255L95 will be used for the spectral nudging in the atmospheric general circulation model ECHAM6. The data processing consists of two steps: (i) vertical interpolation and (ii) transformation into spectral space on each of the 95 sigma-hybrid levels. The temperature and horizontal wind components of the NCEP-1 data are interpolated in the vertical from pressure coordinates to the 95 sigmahybrid levels of ECHAM6. In this step, the orography of ECHAM6 interpolated onto the T62 Gaussian grid is taken into account. In the second step, divergence and vorticity of the wind field are calculated from $u$ and $v$, and the four quantities vorticity, divergence, atmospheric temperature, and the logarithm of the surface pressure (in the following $d v t p$ ) are then transformed to spectral space at spectral resolution T62. Finally, the data are extended to T255 by adding zeros for spectral coefficients with a higher total wavenumber. It should, however, be noted that the time interval of $6 \mathrm{~h}$ between consecutive NCEP-1 time steps limits the lower boundary of the applicable $e$-folding time in order to avoid a nonrealistic evolution of the large-scale fields (Omrani et al. 2012). 
TABLE 1. Analyzed spectral nudging strengths depicted as $e$-folding times $\tau(\min )$ and the corresponding relaxation coefficients $G\left(\times 10^{-5} \mathrm{~s}^{-1}\right)$.

\begin{tabular}{ccccccc}
\hline \hline$\tau_{x}(\min )$ & 5.5 & 10 & 50 & 100 & 500 & 5000 \\
\hline$G\left(\times 10^{-5} \mathrm{~s}^{-1}\right)$ & 300.0 & 166.6 & 32.9 & 16.4 & 3.2 & 0.3 \\
\hline
\end{tabular}

\section{Nudging experiments}

To analyze long-term weather statistics, a long-term and homogeneous meteorological dataset is needed. The most suitable nudging configuration has to be determined for ECHAM6 to produce a new high quality global analysis dataset. This dataset should feature the most realistic representation of meteorological weather phenomena, ranging from the small scale onto the mesoscale and to the large scale. One of our main foci for future studies will be detecting and tracking realistic intense storms, such as polar lows, medicanes, and tropical cyclones. An optimized nudging configuration should yield the most realistic storm simulation. In the following, we give an overview of the studied nudging configurations.

\section{a. Experiment names}

In this article, we will adopt the following name convention for the individual experiments $T_{\text {Number_}} H_{P} \tau_{\text {Number_}} \mathrm{NV}$, where $T_{\text {Number }}$ stands for the wavenumber truncation, HP for the selected height profile, $\tau_{\text {Number }}$ is the $e$-folding time, and NV symbolizes the variables that were spectrally nudged.

The truncation wavenumbers used here range from 5 to 62 . The height profile can be parabolic (pa), plateaushaped (pl), or constant (vc). The $e$-folding time was varied between 5.5 and $5000 \mathrm{~min}$. The variables that were nudged are vorticity $v$, divergence $d$, temperature $t$, and the logarithm of the surface pressure $p$ or combinations of these.

\section{b. The e-folding time}

The first component of the nudging configuration, the nudging strength, will be described by the relaxation time $\tau=1 / G$. The relaxation time describes the $e$-folding time by which the difference in the driving data decays when all other processes are ignored. The larger $\tau$ is, the weaker is the nudging effect. To achieve a realistic time development of high-resolution weather phenomena and a concurrent conservation of the large-scale state of the entire global atmosphere, the choice of the $e$-folding time should be made carefully. In the following, the symbol $\tau_{5.5}$ stands for a chosen $e$-folding time of $5.5 \mathrm{~min}$. The spectral nudging strengths depicted as $e$-folding times and the corresponding relaxation coefficients are illustrated in Table 1.

Table 2 shows the $e$-folding time $\tau$ and its corresponding relaxation coefficient $G$ for each prognostic
TABLE 2. Analyzed $e$-folding times $\tau$ in min for each ECHAM6 variable with $\tau_{\text {echam } \_v}$ for vorticity, $\tau_{\text {echam } \_d}$ for divergence, $\tau_{\text {echam } \_t}$ for temperature, and $\tau_{\text {echam } \_p}$ for the logarithm of surface pressure, as well as the corresponding relaxation coefficient $G$ in $10^{-5}\left(\mathrm{~s}^{-1}\right)$.

\begin{tabular}{ccccc}
\hline \hline Variable & $v$ & $d$ & $t$ & $p$ \\
\hline$\tau_{\text {echam } \_x}(\min )$ & 360 & 2880 & 1440 & 1440 \\
$G\left(\times 10^{-5} \mathrm{~s}^{-1}\right)$ & 4.63 & 0.58 & 1.16 & 1.16 \\
\hline
\end{tabular}

variable vorticity, divergence, temperature, and logarithm of surface pressure in ECHAM6, as used by Jeuken et al. (1996).

\section{c. Height profiles}

Additionally, different functions describing the height dependence of the nudging coefficient were applied. Jeuken et al. (1996) used a height-independent nudging $e$-folding time (differing for $\tau_{\text {echam } \_v}, \tau_{\text {echam } \_d}, \tau_{\text {echam } \_t}$, and $\tau_{\text {echam }} p$, where $v=$ vorticity, $d=$ divergence, $t=$ temperature, and $p=$ the logarithm of surface pressure). However, in regional modeling a vertically increasing strength for spectral nudging is often implemented. Studies by von Storch et al. (2000), Zahn et al. (2008), and Rockel et al. (2008) for regional models like the Regional Model (REMO; Jacob and Podzun 1997) or the climate version of the Lokalmodell (CCLM) of the German Weather Service (Rockel et al. 2008; Steppeler et al. 2003) use spectral nudging with a vertical height profile starting above a level of $850 \mathrm{hPa}$. The strength increases quadratically, like a parabola (hereafter abbreviated by pa; Fig. 1a), up to the model's top. In the present study a global setup is used, which includes high mountains in North and South America as well as in Asia. Therefore, vertical profiles were chosen that only start at the $750-\mathrm{hPa}$ pressure level and end sharply at $3 \mathrm{hPa}$, as above this level no NCEP-1 data are available. Close to the surface the ECHAM6 flow should develop freely as most regional processes take place there. We also tested a plateau-shaped profile (hereafter denoted as pl; Fig. 1b), which is nearly constant between the two considered pressure levels. Outside of this zone of maximum strength of nudging, values decrease rapidly. Figure $1 \mathrm{c}$ shows the height-constant profile (hereafter abbreviated as vc) for the relaxation coefficients for the four prognostic ECHAM6 variables used by Jeuken et al. (1996) and Kaas et al. (2000). The nudging is applied at levels of the ECHAM6-hybrid vertical coordinate, and in Fig. 1 pressure values were deduced from these levels assuming a surface pressure of $1013.25 \mathrm{hPa}$. Note that the pressure of a hybrid surface is significantly lower in the lower atmosphere above mountains where an upward shift of the nudging profile occurs. This approach offers the advantage that nudging 
a)

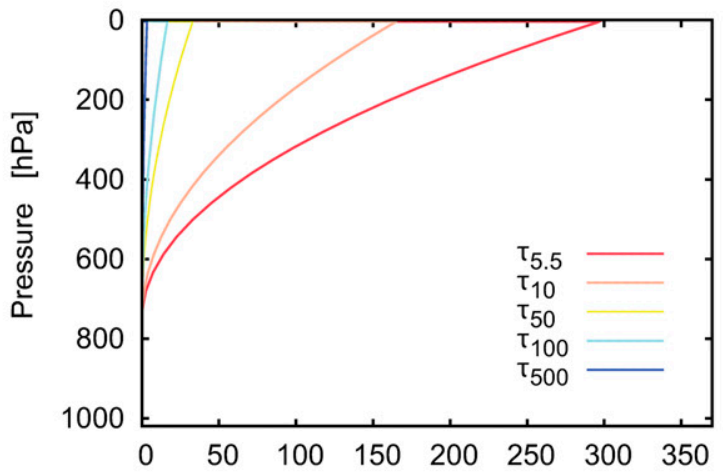

b)

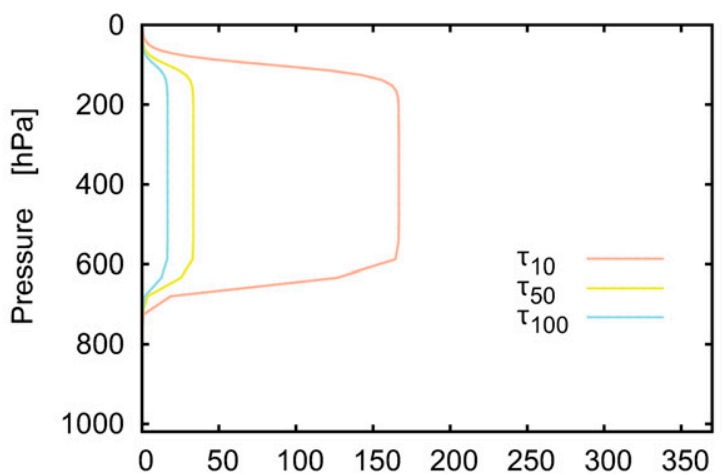

c)

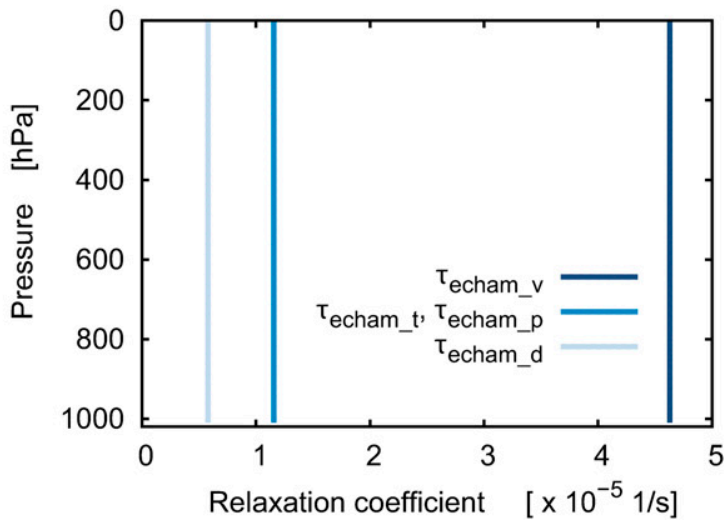

FIG. 1. Different vertical profiles of the relaxation coefficient $G\left(\times 10^{-5} \mathrm{~s}^{-1}\right)$. (a) Profile in the form of a parabola (pa), (b) profile in form of a plateau ( $\mathrm{pl}$ ), and (c) a vertically constant profile (vc) separated for the meteorological variables divergence (light blue line), temperature, logarithm of surface pressure (blue line), and vorticity (dark blue line) as used in Jeuken et al. (1996) and Kaas et al. (2000). The various profiles in (a) and (b) refer to the $e$-folding times 5.5 (red), 10 (orange), 50 (yellow), 100 (light blue), and $500 \mathrm{~min}$ (dark blue). The profile for $\tau_{5000}$ is not shown in (a) because the relaxation coefficient is too small for the display. Note the different scale in (c).

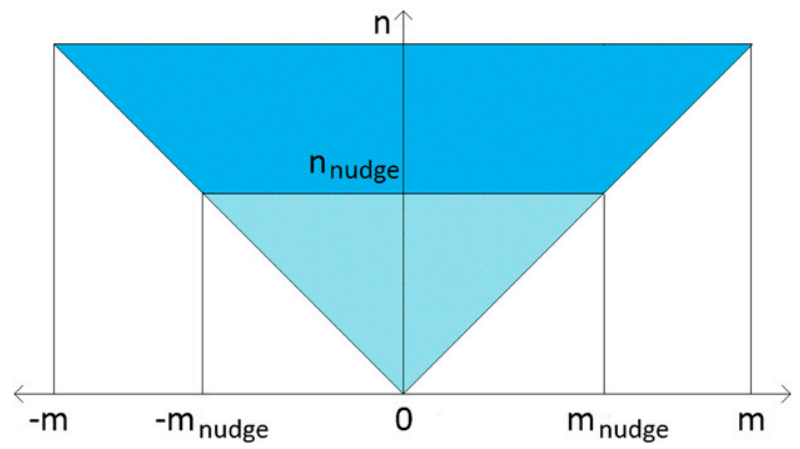

FIG. 2. Triangular truncation. The letters $m$ and $n$ denote zonal and total wavenumbers, respectively. All spectrally nudged areas are colored in light blue. Areas that were not spectrally nudged are displayed in dark blue.

is used in a terrain-following manner in the lower troposphere and at pressure levels in the upper atmosphere.

\section{d. Horizontal profiles of spectral coefficients in the wavenumber spectrum}

For the spectral truncation of the nudging fields a triangular truncation was chosen (Fig. 2). Triangular truncation means that only spectral coefficients with total wavenumbers less than $n_{\text {nudge }}$ are nudged while for a zonal truncation all spectral coefficients below a zonal wavenumber $m_{\text {nudge }}$ are incorporated in the nudging procedure. The illustrated triangle shows only the common intersection of the NCEP-1's and ECHAM6's spectral space up to $n=62$. The nudged wavenumber sectors are shown in light blue. The part of the triangle where no nudging takes place is shaded in dark blue. In the former ECHAM (ECHAM3-ECHAM5) nudging studies (Jeuken et al. 1996; Bauer et al. 2008; Eden et al. 2012), the authors did not select wavenumbers for relaxation.

First, the effect of the truncation wavenumber for the triangular truncation of the spectrally nudged ECHAM6 model will be investigated in comparison with the reanalysis data. The selected truncation wavenumbers are 5 (T05, $\sim 8000-\mathrm{km}$ wavelength), 11 (T11, $\sim 3636-\mathrm{km}$ wavelength), 21 (T21, 1905-km wavelength), 30 (T30, $\sim 1333$-km wavelength), 42 (T42, 952-km wavelength), and 62 (T62, $\sim 645-\mathrm{km}$ wavelength). The agreement with ERA-Interim is analyzed for different types of truncation. Next, the influence of the chosen vertical profile (pa, $\mathrm{pl}$, or vc) and nudging strength (from $\tau_{5.5}$ to $\tau_{5000}$ ) is examined and discussed. Finally, the accordance between ERA-Interim and different spectrally nudged variables is analyzed. The various sensitivity experiments performed are outlined in Table 3.

Additionally, we performed two experiments, one without any spectral nudging and the other using the spectral nudging configuration after Jeuken et al. (1996), 
TABLE 3. Combinations of the nudging parameters in the various experiments. The last column provides the selected vertical nudging profile. The $x$ in the experiment name is a placeholder for the parameter that was varied.

\begin{tabular}{|c|c|c|c|c|c|c|c|c|}
\hline \multirow{3}{*}{ Truncation $(n)$} & Tx_pa_ $\tau_{10 \_} d v$ & 5 & 11 & 21 & 30 & 42 & 62 & pa-height profile \\
\hline & $T x \_p l \_\tau_{10} \_d v$ & 5 & - & 21 & 30 & 42 & 62 & pl-height profile \\
\hline & $T x \_p l \_\tau_{50 \_} d v$ & - & - & 21 & 30 & 42 & - & pl-height profile \\
\hline \multirow{2}{*}{$e$-folding time (min) } & T42_pa $\_\tau_{x-} d v$ & 5.5 & 10 & 50 & 100 & 500 & 5000 & pa-height profile \\
\hline & T42_pl_ $\tau_{x \_} d v$ & - & 10 & 50 & 100 & - & - & pl-height profile \\
\hline \multirow[t]{2}{*}{ Variable } & T42_pa_ $\tau_{10 \_} x$ & $v$ & $d v$ & $d v t$ & $d v t p$ & - & - & pa-height profile \\
\hline & T42_vc_ $\tau_{\text {echam } \_x}$ & $v$ & $d v$ & $d v t$ & $d v t p$ & - & - & vc-height profile \\
\hline
\end{tabular}

where all available spectral coefficients were nudged height independently up to total wavenumber 62 $\left(\mathrm{T} 62 \_\mathrm{vc} \_\tau_{\text {echam } \_d v t p}\right)$.

\section{Results}

Because of computational restrictions and the large number of sensitivity experiments performed, most of the simulations carried out with modified nudging configurations have a length of only 2 months and an additional spinup time of another month. We focus on October 2004 because it was a storm-active month, which is one of our main research foci for future applications of this GCM model setup. Additionally, extreme events such as storms are a demanding task for climate models and thus present an appropriate test case for sensitivity studies. To gain a restart file for the numerous experiments in October, we performed a 1-yr experiment with ECHAM6 by using the spectral nudging configuration T42_pa $\tau_{10} \_d v$. The simulation was started during October 2003 so as to let the model adapt over a sufficiently long period to the nudging mode.

\section{a. Wavenumber spectrum}

The calculation of the wavenumber spectrum is one of the statistical methods used to investigate the degree of correlation among the spectral coefficients (imaginary and real) between the spectrally nudged ECHAM6 and NCEP-1. The effect of spectral nudging on vorticity is displayed in Fig. 3. A very high level of agreement can be stated for wavenumbers up to 42 at $500 \mathrm{hPa}$ in the simulation T42_pa_ $\tau_{10} d v$ (Fig. 3c). The part where the nudging takes place is characterized by high values close to one. The nonnudged part shows much smaller correlations. Although the spectrally nudged domain is sharply confined at total wavenumber $n=42$, it seems that the nudged field triggers an increase in correlation of the adjacent higher wavenumbers that were not nudged. Varying the nudging strength $\tau_{x}$ for the setup T42_pa $\_\tau_{\mathrm{x}-} d v$ has a strong impact on the simulated fields. This is shown in Figs. 3a-c for the $e$-folding times $\tau_{5000}, \tau_{100}$, and $\tau_{10}$. Time $\tau_{5000}$ shows small correlation values between the spectral coefficients of nudged
ECHAM6 and NCEP-1 and only for the large scales up to total wavenumber $n=5$. For $n>5$, the correlation is very small and partly negative (Fig. $3 a$ ). This nudging configuration virtually resembles the results of a nonnudged run where nearly all spectral coefficients have very small or no correlation with NCEP-1 (not shown). With increasing nudging strength the domain with higher correlation values becomes larger.

We evaluated the effects of nudging different atmospheric variables for varying height profiles. The vertically constant ECHAM6 spectral nudging (T42_vc_ $\tau_{\text {echam } \_x}$ ) for vorticity only gives high correlations comparable to the plateau-shaped profile. The additional nudging of surface pressure reveals nearly no change. However, adding divergence and temperature as nudging variables leads to further increases in the correlation values. Since the nudging is not applied in the boundary layer for the parabolic and plateau profiles, the correlations in spectral space become smaller for $1000-\mathrm{hPa}$ vorticity. However, the reduction in the correlation is smaller for the plateau nudging profile, so that in the experiment $\mathrm{T} 42 \_\mathrm{pl} \_\tau_{10} d v$ the correlation in the nudged range of the spectrum is always above $70 \%$. For very small total wavenumbers $(<21)$ the correlation remains close to $90 \%$ at $1000 \mathrm{hPa}$ (not shown).

\section{b. Energy spectra}

Energy spectra can deliver valuable information about the transfer of turbulent enstrophy from large to small scales in the atmosphere. This can be used to show how the spectral nudging modifies this transfer and if it possibly leads to spurious results. In Fig. 4, the power spectra of the global kinetic energy at the hybrid levels 75,82 , and 95 , which approximately correspond to $250-$ 500-, and 1000-hPa pressure altitude over flat terrain, are shown for NCEP-1 (dark blue line) and the ECHAM6 experiment T42_pa_ $\tau_{10} d v$ (light blue line). A formula described by Nozawa and Yoden (1997) that relates kinetic energy to spectral vorticity coefficients was used to calculate the spectrum. It was found that even in the non-nudging experiment the agreement between ECHAM6 and NCEP-1 is large. The usage of spectral nudging shifts the energy spectrum closer to the NCEP-1 
a)
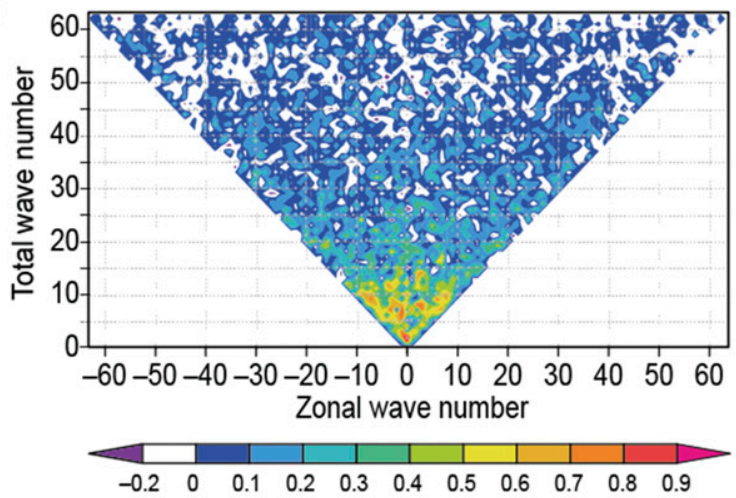

b)

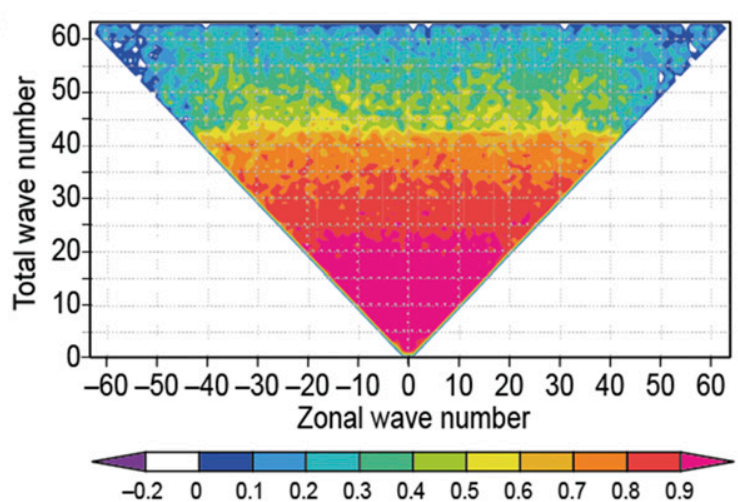

c)

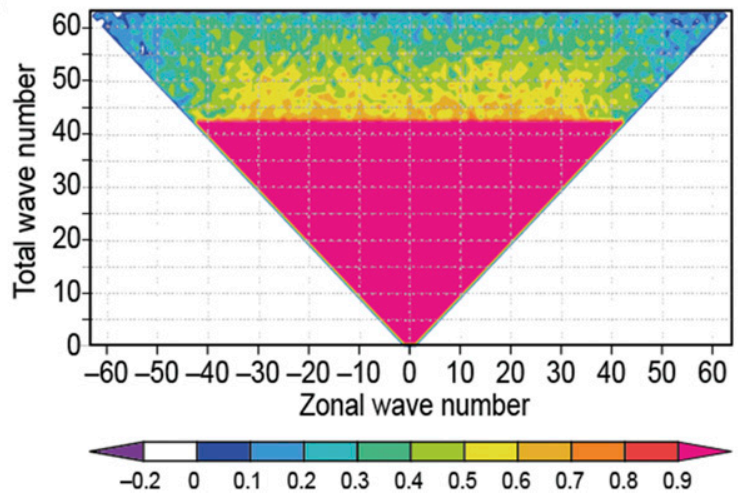

FIG. 3. The correlations of vorticity at $500 \mathrm{hPa}$ in spectral space between the nudged ECHAM6 model fields and the corresponding NCEP-1 data for the (a) T42_pa_ $\tau_{5000 \_} d v$, (b) T42_pa_ $\tau_{100 \_} d v$, and (c) T42_pa_ $\tau_{10} d v$ runs.

spectrum in the nudged wavenumber range. For total wavenumbers up to 42 (Tx_pa_ $\left.\tau_{10 \_} d v\right)$, the power spectra of both datasets are nearly identical at 250 and $500 \mathrm{hPa}$ for the parabolic profile. The well-coinciding curves for lower wavenumbers demonstrate that the nudging of large-scale information works correctly in this run. For higher wavenumbers, ECHAM6 has a larger amount of kinetic energy. The inertial subrange splits into a low-wavenumber part $\left(\sim n^{-5 / 3}\right)$ and a high-wavenumber a)

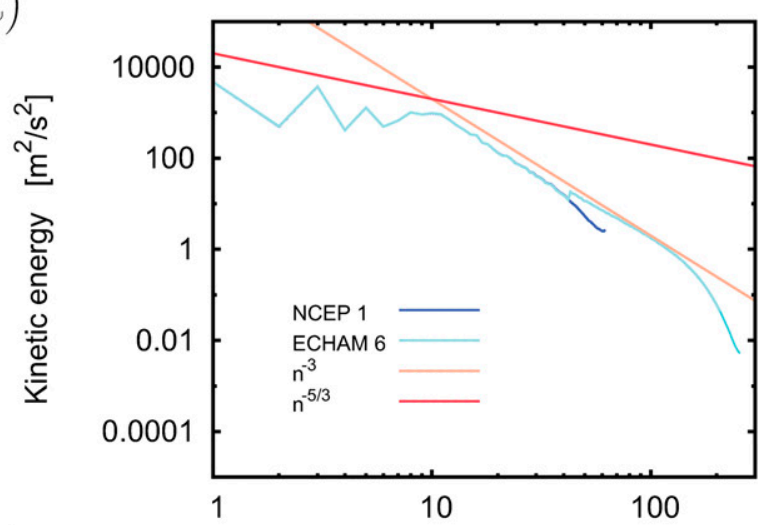

b)

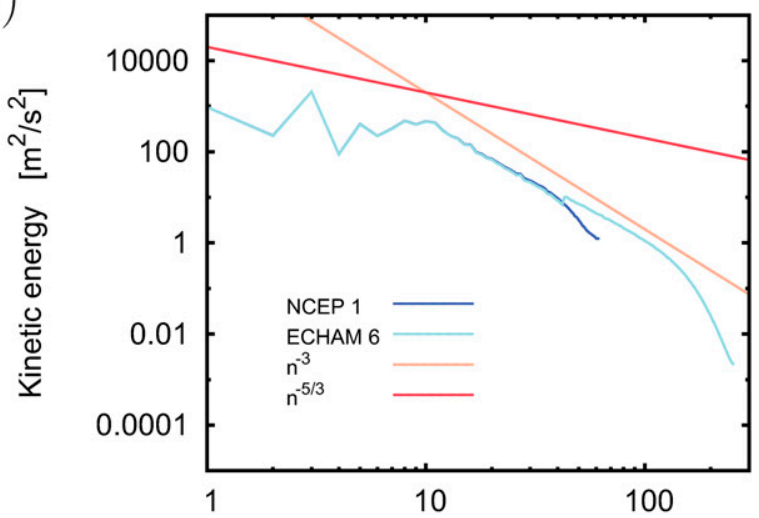

c)

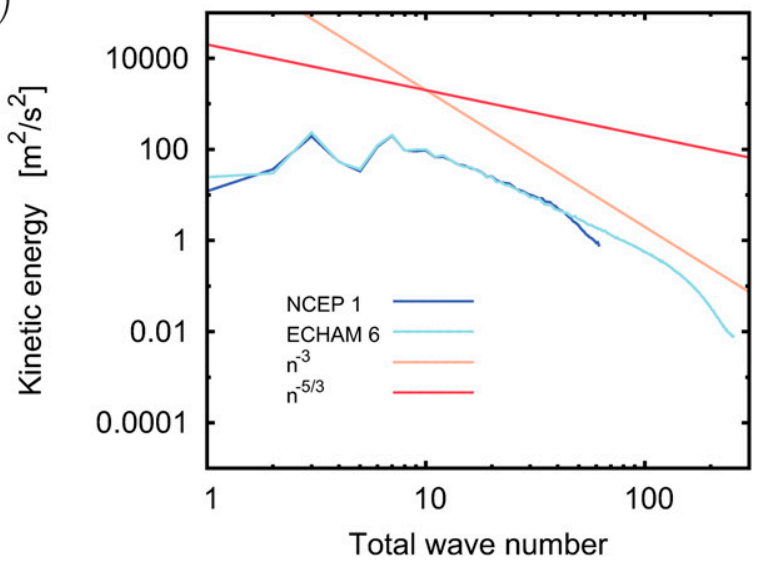

FIG. 4. Kinetic energy spectra for ECHAM6 (light blue) and NCEP-1 (dark blue) for experiment T42_pa_ $\tau_{10 \_} d v$ at hybrid levels (a) 75 (corresponding to $250 \mathrm{hPa}$ ), (b) 82 (corresponding to $500 \mathrm{hPa}$ ), and (c) 95 (corresponding to $1000 \mathrm{hPa}$ ). The orange lines are for $n^{-3}$ and the red ones for $n^{-5 / 3}$.

part $\left(\sim n^{-3}\right)$. The latter ranges to much higher wavenumbers in ECHAM6. In the boundary layer the agreement between both spectra deviates for total wavenumbers 1 and 2. The slopes of the spectra become flatter in the lower part of the atmosphere. By increasing the nudging wavenumber, a more accentuated dip appears at the 
a)

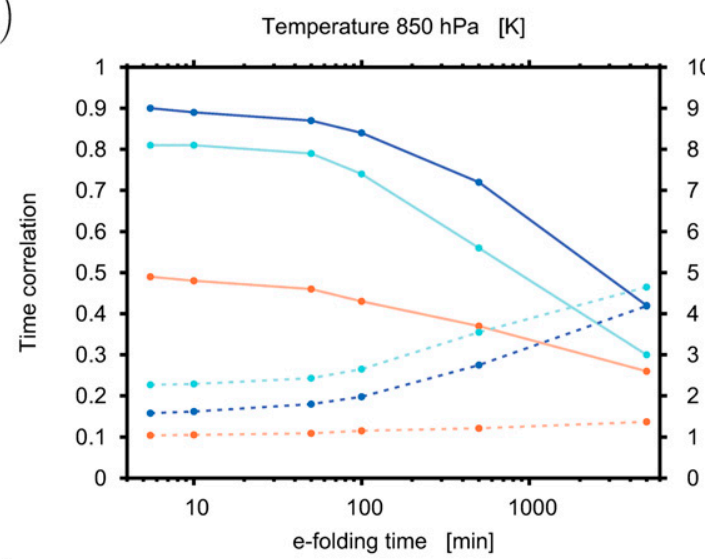

b)

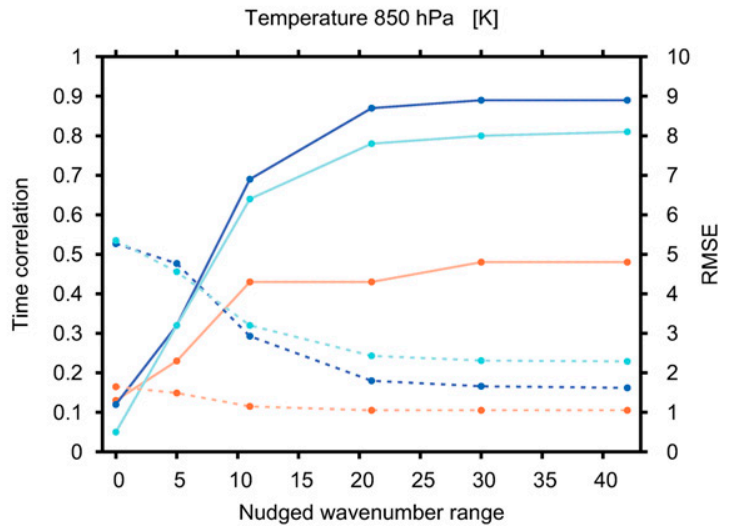

FIG. 5. (a) Time correlations (solid lines) and RMSEs (dashed lines) for the temperature at $850 \mathrm{hPa}$ as a function of $e$-folding time $\tau$. Shown are different regions, the tropical zone (orange), extratropics of the Northern Hemisphere (dark blue), and extratropics of the Southern Hemisphere (light blue). (b) As in (a), but as a function of the nudging truncation (wavenumber range).

transition point between the nudged and nonnudged spectral ranges (wavenumber 42). We think that this dip is a result of the different kinetic energy levels of ECHAM6 and NCEP-1. ECHAM6 generally has a higher level and is reduced by the nudging to the lower NCEP-1 energy level for smaller wavenumbers.

\section{c. Comparison of 850-hPa temperature and 200-hPa zonal wind fields with ERA-Interim}

In this section, we analyze the agreement between the nudged ECHAM6 and the ERA-Interim (Dee et al. 2011) by calculating the statistical measures time correlation (tc) and root-mean-square error (RMSE) for meteorological quantities at their typical levels. For the comparisons, we chose temperature $(850 \mathrm{hPa})$ and zonal wind $(200 \mathrm{hPa})$ because they are relevant variables for the entire troposphere. To depict the tc and RMSE in a more compact form, three zones were defined: the extratropics in the Northern Hemisphere $\left(22.5^{\circ}-90^{\circ} \mathrm{N}\right)$, the tropical a)

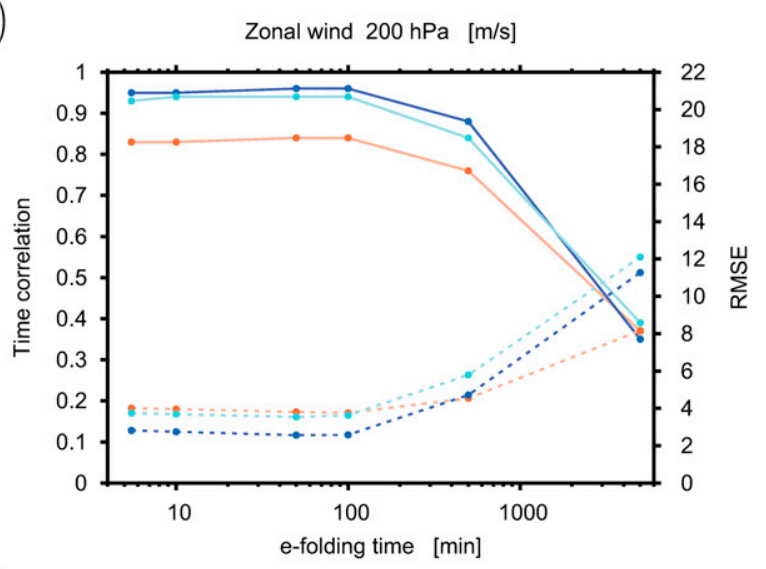

b)

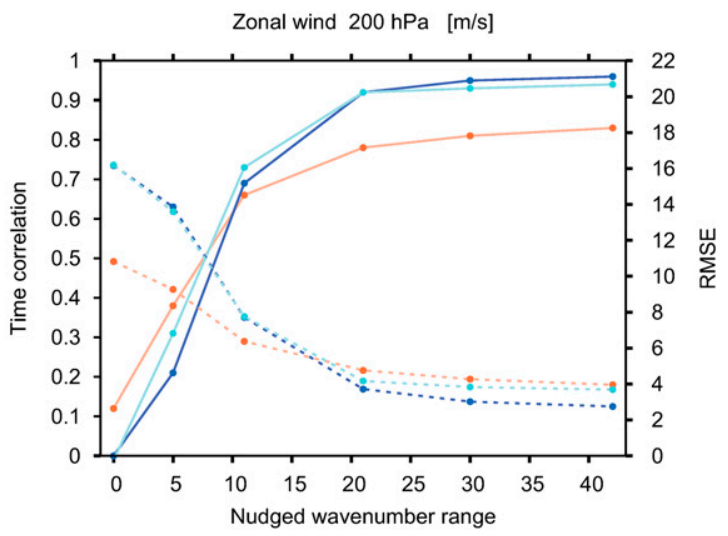

FIG. 6. As in Fig. 5, but for the 200-hPa zonal wind.

zone $\left(22.5^{\circ} \mathrm{N}-22.5^{\circ} \mathrm{S}\right)$, and the extratropics in the Southern Hemisphere $\left(22.5^{\circ}-90^{\circ} \mathrm{S}\right)$. Figure 5a illustrates the corresponding changes for tc and RMSE as a function of nudging $e$-folding time. A large nudging time scale of $\tau_{5000}$ shows a distinct decrease of the tc and a corresponding increase of RMSE in the extratropical regions. The lower the applied $e$-folding time, the better the results are with regard to tc and RMSE (experiment T42_pa_ $\tau_{10 \_} d v$ ). Close to the equator, the tc and RMSE show less agreement with ERA-Interim and the influence of the nudging strength decreases. Figure $5 \mathrm{~b}$ shows the tc and RMSE as a function of nudging wavenumber, which ranges from nonnudged T0 to nudged wavenumber T42. Starting from $\mathrm{T} 0$ and moving toward T42, the correlation grows strongly up to T21 and then shows nearly constant high values for the extratropical latitudes up to T42. The correlation for the Northern Hemisphere exhibits higher values than those for the Southern Hemisphere. In the tropics, the tc is clearly smaller and its upward trend already ends at wavenumber 11.

Figures $6 \mathrm{a}$ and $6 \mathrm{~b}$ show the dependencies of tc and RMSE to the nudging $e$-folding times and truncation for the zonal wind at $200 \mathrm{hPa}$. In the higher-wavenumber 
range, the tc for zonal wind is higher than for temperature for the three selected regions. A clear decrease in tc starts at truncation values below T21 (Fig. 6b). An opposite trend was found in the RMSE. Interestingly, the difference between the tc in the tropics and extratropics is much lower for $200-\mathrm{hPa}$ zonal wind than for $850-\mathrm{hPa}$ temperature (see Fig. 5).

\section{d. Snapshots of nudged and nonnudged global 2-m temperature field}

Figure 7 a shows the 2-m temperature dry adiabatically reduced to sea level in simulation T42_pa_ $\tau_{10 \_} d v$ at a single time while in Fig. $7 \mathrm{~b}$ the differences between these results and those of NCEP-1 are displayed. Note that the 2-m temperature was not nudged for this simulation. Larger deviations are mainly visible over land areas and likely occur as a result of the higher resolved orography in ECHAM6. In addition, too high temperatures result over the Midwest and the Sahara while too low temperatures can be seen over a large area of the Antarctic. Comparing the 2-m temperature of the nonnudged simulations with NCEP-1 (Fig. 7c) reveals much larger differences. This simulation without spectral nudging was performed in accordance with the Atmospheric Model Intercomparison Project standard (Gates 1992) (in the following denoted as AMIP-type simulation) using monthly SSTs and sea ice information of NCEP-1. As only these variables are provided at the lower boundary, the hindcast skills of this AMIP-type simulation are limited. The large differences compared to NCEP-1 are not surprising as the atmosphere has a predictability time scale, that is much below the integration time of the model simulation without nudging. Therefore, atmospheric fields of the nonnudged simulations generally do not correlate well with the NCEP-1 reanalysis results. Spectral nudging decreases these differences quite efficiently, with the exception of the Antarctic region. It is important to note that here just a single GCM without spectral nudging was shown. An ensemble simulation would lead to very different results between the ensemble members since the importance of the initial conditions is large when not using spectral nudging (Weisse and Feser 2003).

\section{e. Comparison of 2-m temperature fields with ERA-Interim}

For these comparisons the atmospheric fields were spatially filtered in order to see differences among the various spatial scales. Figure 8 shows the time correlation for the low-pass-filtered and thus large-scale field of temperature (dry adiabatically reduced from $2 \mathrm{~m}$ to sea level) for October 2004. Before calculating the time correlation, we selected all of the low wavenumbers up
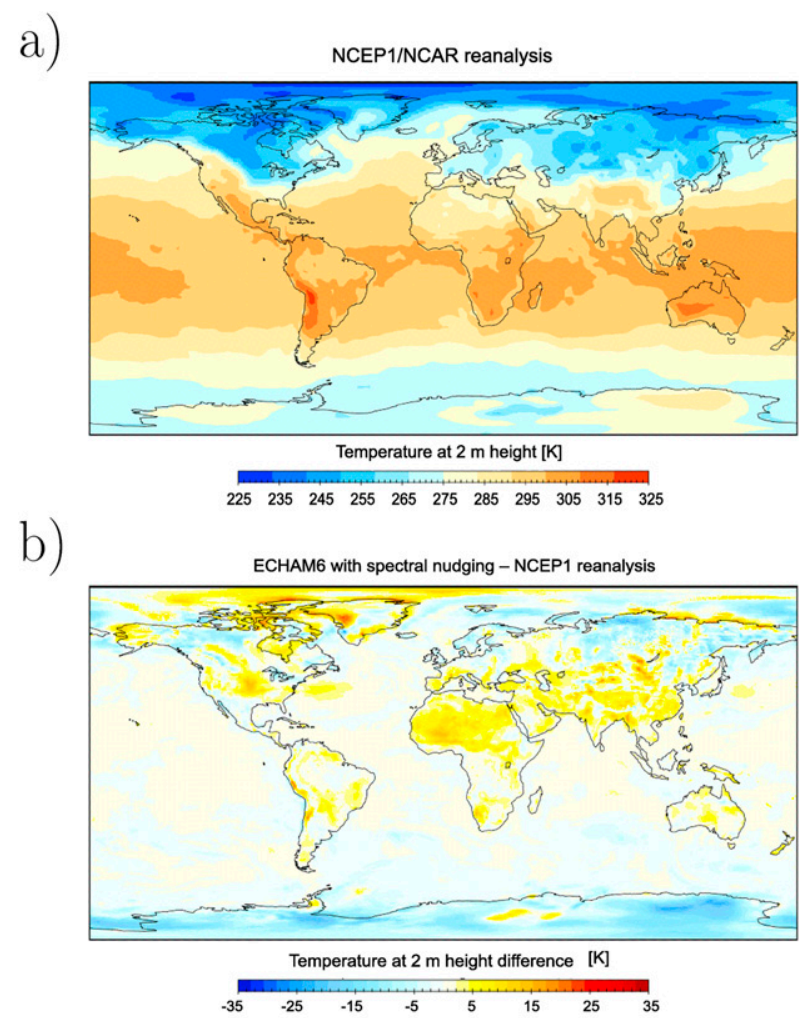

c)

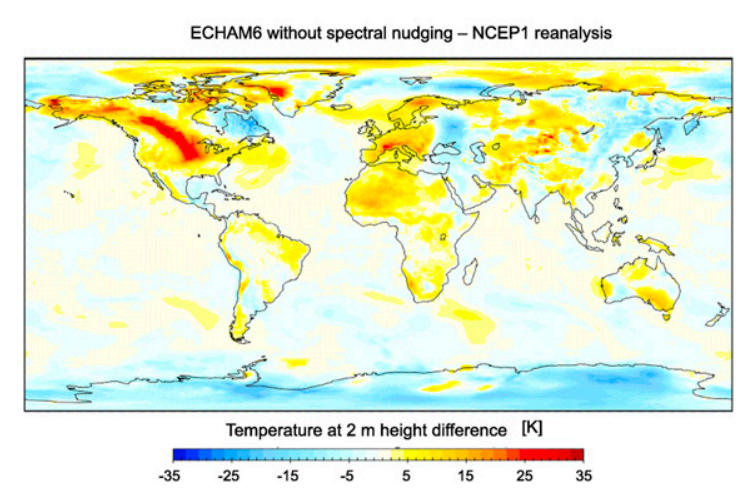

FIG. 7. (a) NCEP-1 temperature reduced dry adiabatically from $2 \mathrm{~m}$ to sea level at 0000 UTC 30 Jan 2004; the color scale is from 225 to $325 \mathrm{~K}$ in increments of $10 \mathrm{~K}$. (b) Difference between ECHAM6 with spectral nudging (experiment T42_pa_ $\tau_{10 \_} d v$ ) and NCEP-1; the color scale is from $-35 \mathrm{~K}$ to $+35 \mathrm{~K}$ in increments of $10 \mathrm{~K}$. (c) Difference between ECHAM6 without spectral nudging and NCEP-1; the color scale is as is in (b).

to total wavenumber 25 so that a low-pass-filtered field remained. Figure 8 displays the time correlation of experiment T42_pa_ $\tau_{10} d v$ with ERA-Interim. In most regions the time correlation exceeds a value of 0.75 , which shows that the ECHAM6 results are close to the reference reanalysis. However, over tropical oceans the time correlation is close to zero or even negative. These results may indicate that ECHAM6 has deficiencies in correctly reproducing the boundary layer temperature 

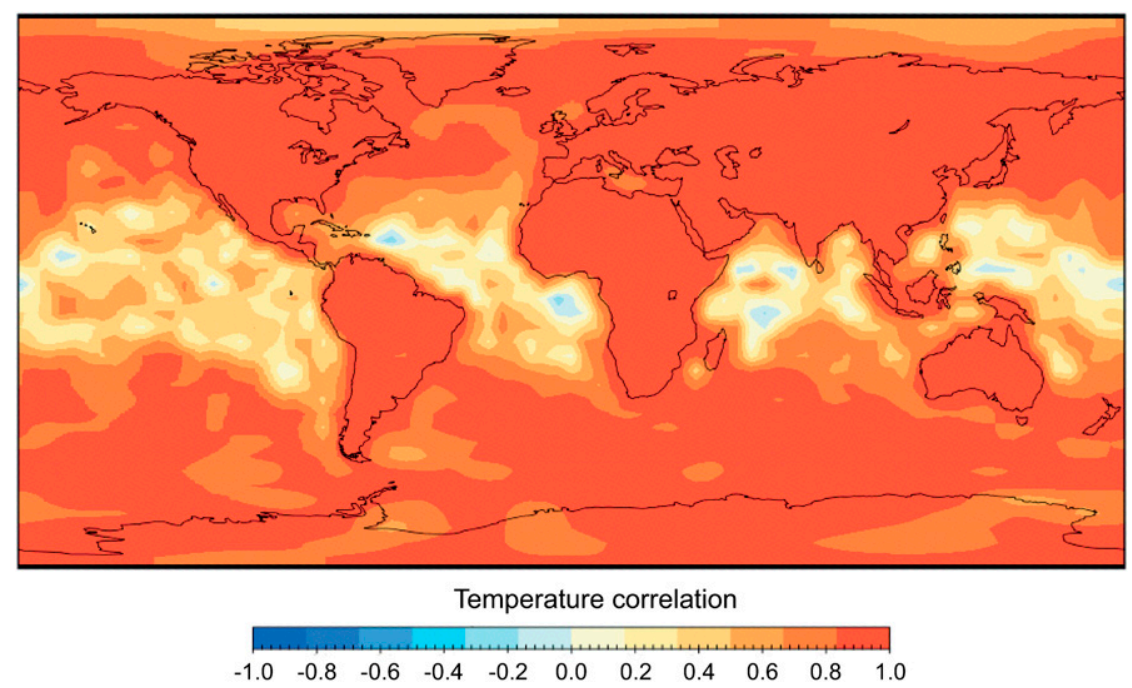

FIG. 8. Time correlation of 2-m temperature reduced dry-adiabatically from $2 \mathrm{~m}$ to sea level, (low-pass filtered) during October 2004 between ECHAM6 experiment T42_pa_ $\tau_{10 \_} d v$ and ERA-Interim.

in these regions. As suggested by Bauer (2000), it can be presumed that ECHAM cannot resolve weather phenomena such as the inner tropical convergence zone and its embedded convective processes close to the equator. However, these negative values can also stem from the different reanalyses showing weak correlations between them. Note that locally negative correlation values are to be expected if small field samples are random.

Figure 9 shows spatially filtered temperature reduced dry adiabatically from $2 \mathrm{~m}$ to sea level at 0000 UTC 30 January 2004 for ERA-Interim, NCEP-1, the spectrally nudged ECHAM6 experiment T42_pa_ $\tau_{10} d v$, and nonnudged ECHAM6 for Europe. Also shown are unfiltered sea level pressure isobars. Wavenumbers were selected (corresponding to a gridpoint distance ranging from 300 to $380 \mathrm{~km}$ ) for the $2-\mathrm{m}$ temperature field so that a bandpass-filtered regional temperature field resulted. Feser (2006) suggested such a selection of regional scales in order to detect potential added value of a higher-resolution climate model simulation in comparison to its coarser forcing data. ERA-Interim shows low pressure systems over the Norwegian Sea, the southern tip of Sweden, and Italy while a high occurs over central France. The low pressure systems are all well captured by NCEP-1 and ECHAM6 with spectral nudging. The central pressures of these lows are somewhat smaller in the nudged ECHAM6, which can possibly be explained by the high model resolution. The regional temperature anomalies of ERA-Interim were also reproduced by ECHAM6 with spectral nudging. In some regions a higher degree of agreement with ERAInterim can be seen compared with NCEP-1. For example, the warm anomaly east of Great Britain is too high in NCEP-1 compared to ERA-Interim while ECHAM6 reproduces this anomaly with the correct amplitude. At other locations ECHAM6 is closer to NCEP-1 as can be seen, for example, in the cold anomaly at $75^{\circ} \mathrm{N}$ and $5^{\circ} \mathrm{W}$ (close to the northwestern boundary of the map).

The nonnudged ECHAM6 experiments reveal large differences in the sea level pressure and temperature distributions in comparison to ERA-Interim. For the spectrally nudged simulation this internal model variability and the dependence on the initial conditions is greatly reduced.

\section{f. Similarity for different spatial scales}

To analyze the similarity between two datasets, the similarity measure first proposed by von Storch et al. (2000) and later used by Liu et al. (2012) is an appropriate statistical method. This measure is given by

$$
P(t)=1-\frac{\left\langle\left[\Psi(\mathbf{r}, t)-\Psi^{*}(\mathbf{r}, t)\right]^{2}\right\rangle}{\left\langle\Psi(\mathbf{r}, t)^{2}\right\rangle},
$$

where $\mathbf{r}$ denotes the position vector, $\Psi$ a model field variable, $\Psi^{*}$ the corresponding global forcing field variable (here NCEP-1), and $\langle\cdot\rangle$ the global average. The similarity was calculated for the large-scale field part that covers the nudged spectral range and for the regional-scale field part, which includes wavenumbers larger than $n_{\text {nudge }}$. These measures are referred to as $P_{g}$ and $P_{r}$, respectively. The calculations of similarity were done in spectral space. For a spectrally nudged dataset, $P_{g}$ should be close to 1 as the 

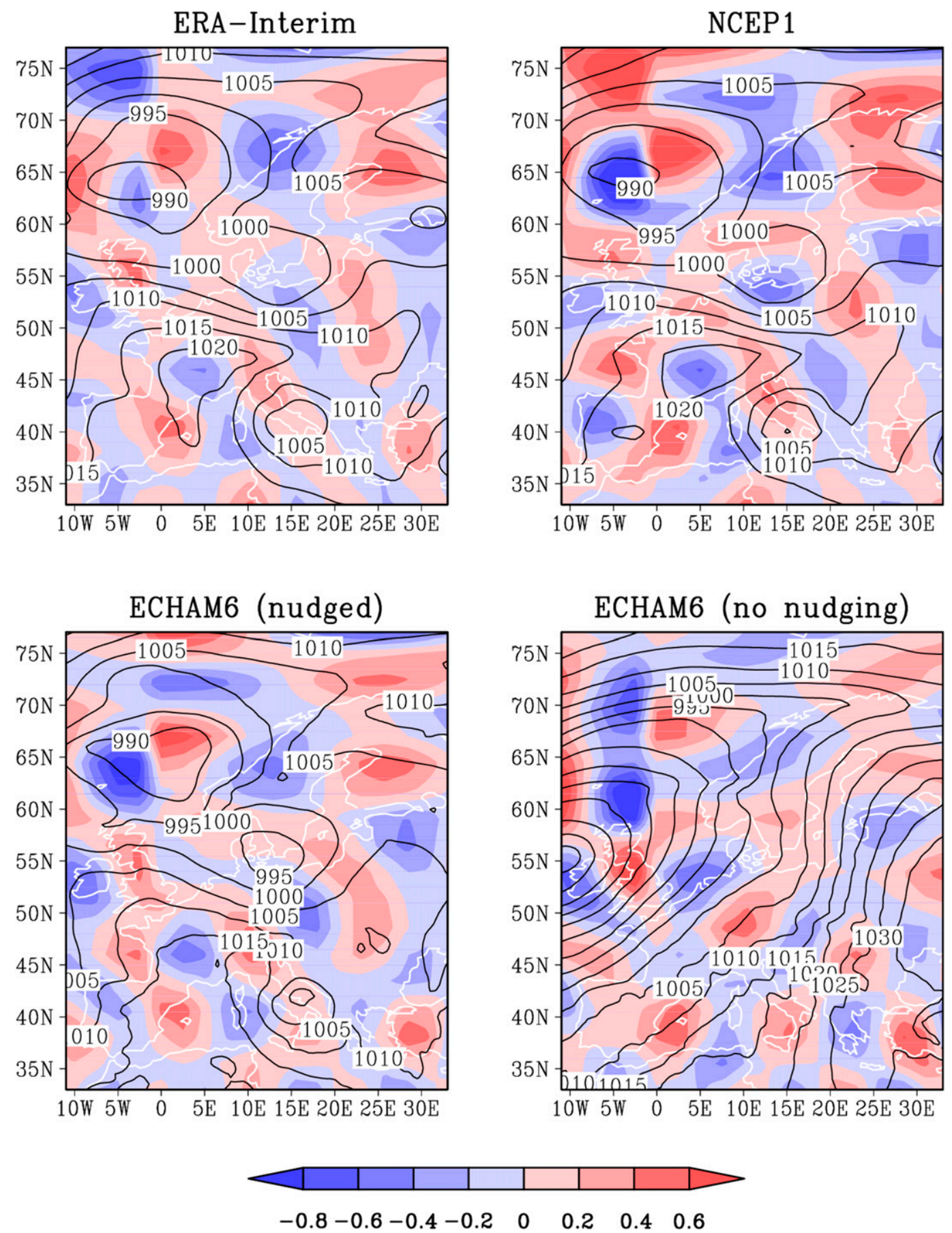

FIG. 9. Spatially filtered temperature reduced dry adiabatically from $2 \mathrm{~m}$ to sea level at the regional scale (color shading, K) and unfiltered sea level pressure (contours with interval of $5 \mathrm{hPa}$ ) at 0000 UTC 30 Jan 2004 for (top left) ERA-Interim, (top right) NCEP-1, (bottom left) spectrally nudged ECHAM6 experiment T42_pa_ $\tau_{10 \_} d v$, and (bottom right) nonnudged ECHAM6.

nudging brings the fields close to the global forcing data. The measure $P_{r}$ should differ substantially from 1 as at these local scales, the model should deviate clearly from its forcing data in order to show new, regional features (which could not be resolved in the forcing reanalysis) and thus potential added value. This potential added value could be verified with suitable observational data or with reanalysis data having a higher resolution. 


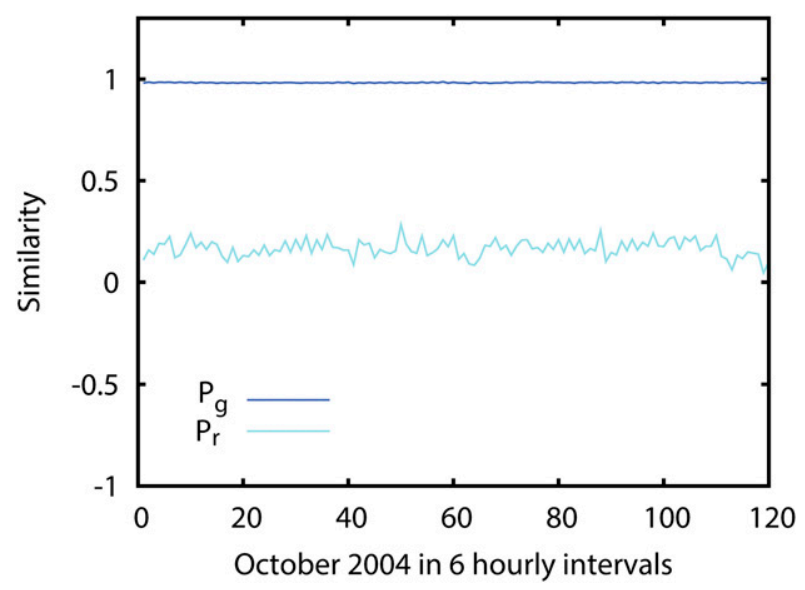

FIG. 10. The large- and small-scale similarities, $P_{g}$ (dark blue) and $P_{r}$ (light blue), respectively, between the nudged ECHAM6 vorticity fields (run T42_pa_ $\tau_{10} \_d v$ ) at $500 \mathrm{hPa}$ and the corresponding NCEP-1 data.

Figure 10 shows time series of $P_{g}$ and $P_{r}$ for the vorticity field at $500 \mathrm{hPa}$ of the experiment T42_pa_ $\tau_{10 \_} d v$. Both parameters show almost no trend while $P_{g}$ is almost constant at a value close to 1 . Therefore, the spectral nudging effectively dampens large deviations from the NCEP-1 vorticity field in the nudged part of the spectrum. On the contrary, the regional-scale part of the spectrum features fluctuations and its mean value is 0.16 , showing that ECHAM is simulating its own regional weather states. Tables 4-6 contain the time-averaged similarities for various experiments at the different model levels. We see that the $e$-folding time has a strong impact on the $P_{g}$ value in the parabolic nudging profile experiments (T42_pa_ $\tau_{x \_} d v$; see Table 4).

An $e$-folding time larger than $100 \mathrm{~min}$ leads to a dramatic drop in similarity at the 500-hPa level and a time of $5000 \mathrm{~min}$ leads to negative values, as such long $e$-folding times correspond to a nonnudged state. The similarity is smaller at $1000 \mathrm{hPa}$, which shows the limited influence of the spectrally nudged upper-level flow on the large-scale flow close to the surface where no nudging was applied. The plateau-shaped height

TABLE 4. The large and small-scale similarities $P_{g}$ (left) and $P_{r}$ (right) between the vorticity in ECHAM6 and the corresponding NCEP-1 data for different $e$-folding times $\tau(\mathrm{min})$ and pressure levels $(\mathrm{hPa})$ for experiments T42_pa_ $\tau_{x \_} d v$ for a parabolic nudging profile.

\begin{tabular}{cccc}
\hline \hline T42_pa_$\tau_{x \_} d v$ & $250 \mathrm{hPa}$ & $500 \mathrm{hPa}$ & $1000 \mathrm{hPa}$ \\
\hline$\tau_{5.5}$ & $+0.99 /+0.21$ & $+0.99 /+0.17$ & $+0.60 /+0.07$ \\
$\tau_{10}$ & $+0.99 /+0.21$ & $+0.98 /+0.16$ & $+0.56 /+0.03$ \\
$\tau_{50}$ & $+0.98 /+0.19$ & $+0.89 /+0.09$ & $+0.43 /-0.06$ \\
$\tau_{100}$ & $+0.95 /+0.13$ & $+0.79 /+0.00$ & $+0.33 /-0.18$ \\
$\tau_{500}$ & $+0.54 /-0.42$ & $+0.19 /-0.35$ & $-0.10 /-0.35$ \\
$\tau_{5000}$ & $-0.39 /-0.51$ & $-0.52 /-0.39$ & $-0.48 /-0.45$ \\
\hline
\end{tabular}

TABLE 5. As in Table 4, but for experiment T42_pl_ $\tau_{x \_} d v$ for a plateau-shaped nudging profile. The entries with an em dash (-) indicate that no simulation was performed with the corresponding $e$-folding time.

\begin{tabular}{cccc}
\hline \hline T42_pl_$\tau_{x \_} d v$ & $250 \mathrm{hPa}$ & $500 \mathrm{hPa}$ & $1000 \mathrm{hPa}$ \\
\hline$\tau_{5.5}$ & - & - & - \\
$\tau_{10}$ & $+0.99 /+0.11$ & $+0.99 /+0.17$ & $+0.61 /+0.12$ \\
$\tau_{50}$ & $+0.99 /+0.23$ & $+0.99 /+0.20$ & $+0.65 /+0.12$ \\
$\tau_{100}$ & $+0.98 /+0.23$ & $+0.98 /+0.18$ & $+0.57 /+0.04$ \\
$\tau_{500}$ & - & - & - \\
$\tau_{5000}$ & - & - & - \\
\hline
\end{tabular}

distribution of T42_pl_ $\tau_{x \_} d v$ (Table 5) leads to higher agreement between ECHAM6 and NCEP-1 than the parabolic profile (see Table 4). The similarity for the plateau profile relative to the parabolic profile is up to $24 \%$ higher for $P_{g}$ and up to $22 \%$ higher for $P_{r}$ for an $e$-folding time of $100 \mathrm{~min}$. The larger similarity of $P_{g}$ was rated as being more important than the negative effect of a larger similarity of $P_{r}$, which decreases the potential added value of the ECHAM6 results.

Table 6 shows the similarity values for the ECHAM6 configuration of Jeuken et al. (1996) and Kaas et al. (2000), which include a height-independent spectral nudging up to T42 and an $e$-folding time of more than $100 \mathrm{~min}$ (time is a variable dependent; see Table 2). Additional nudging of the divergent part of the horizontal wind leads to higher values of $P_{r}$ at 200 and $500 \mathrm{hPa}$. Subjoining the temperature to the group of nudging quantities only yields another increase in small-scale similarity, but adding the nudging variable pressure results in a decrease of $P_{r}$. The dependency on variables is similar for the parabolic nudging profile (not shown). Compared to the plateau and parabolic profiles, which use no nudging close to the surface, the height-constant nudging shows higher $P_{g}$ values at $1000 \mathrm{hPa}$, and $P_{r}$ is also increased. This indicates that the desired feature of high values for $P_{g}$ may go along with larger similarities at the regional scale and thus have less potential added value. We recommend not nudging all the way down to the surface, as the model needs some freedom, especially close to the ground, to generate regional weather systems.

TABLE 6 . The large- and small-scale similarities $P_{g}$ (left) and $P_{r}$ (right) between the vorticity in ECHAM6 and the corresponding NCEP-1 data for different nudging variables and height levels in T42_vc_ $\tau_{\text {echam } \_x}$ as given in Jeuken et al. (1996) and Kaas et al. (2000) for different pressure levels.

\begin{tabular}{cccc}
\hline \hline T42_vc_ $\tau_{\text {echam } \_x}$ & $250 \mathrm{hPa}$ & $500 \mathrm{hPa}$ & $1000 \mathrm{hPa}$ \\
\hline$v$ & $+0.93 /+0.15$ & $+0.92 /+0.15$ & $+0.87 /+0.18$ \\
$d v$ & $+0.93 /+0.17$ & $+0.92 /+0.17$ & $+0.87 /+0.19$ \\
$d v t$ & $+0.95 /+0.23$ & $+0.94 /+0.21$ & $+0.89 /+0.23$ \\
$d v t p$ & $+0.95 /+0.22$ & $+0.94 /+0.20$ & $+0.89 /+0.20$ \\
\hline
\end{tabular}


We also investigated the effect of the truncation wavenumber $n_{\text {nudge }}$ on similarity in Tx_pa $\_\tau_{10} d v$ at the 250- and 500-hPa levels (not shown). At $1000 \mathrm{hPa}, P_{g}$ increases with decreasing truncation. The $P_{r}$ values decrease with decreasing truncation wavenumber. This is not surprising, as the spectrum part, where the model can freely evolve, becomes larger as $n_{\text {nudge }}$ decreases. This is in agreement with the findings of Liu et al. (2012) based on a regional model.

\section{g. Comparisons between nudged ECHAM6, NCEP-1, and DWD local observation data}

In this section the added value of the global dynamical downscaling method will be discussed by analyzing the near-surface quantities 2-m temperature (T2M), 10-m wind speed (W10M), and total precipitation. By comparing the spectrally nudged ECHAM6 data and observation data, provided by the German Weather Service [Deutscher Wetterdienst (DWD)], the degree of agreement was evaluated. To compare the time series, the grid points adjacent to selected observation stations were linearly interpolated to the exact coordinates of the observation site. For our study the Hamburg Airport station (at $11 \mathrm{~m}$ above sea level) in northern Germany was chosen. The highest time correlation (hereafter tc) values are about 0.93 and were obtained from the experiment T42_vc_ $\tau_{\text {echam }} d v$ in which the height-independent nudging profile was prescribed. This is because the station data were assimilated in NCEP-1 and thus nudging all the way down to the ground leads to the highest correlations (though it may suppress the formation of regional details). For the experiments without nudging of the boundary layer, the highest tc with 0.92 is shown for T30_pl_ $\tau_{50 \_} d v$. Figure $11 \mathrm{~b}$ shows time series of T2M for this configuration and the observational data. The agreement between these experiments is large except for some deviation in mid-October. Additional nudging of temperature and the logarithm for surface pressure or nudging up to T62 with all variables does not improve the tc (not shown). In addition to tc, the Brier skill score (BSS) was calculated, which is given by

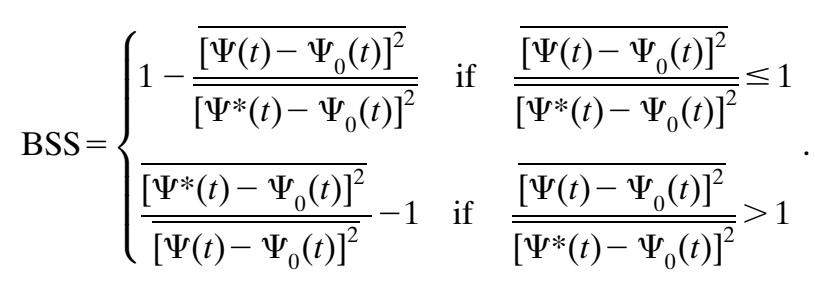

The overbar denotes a time average and the index o indicates the observation data. The BSS is a statistical a)

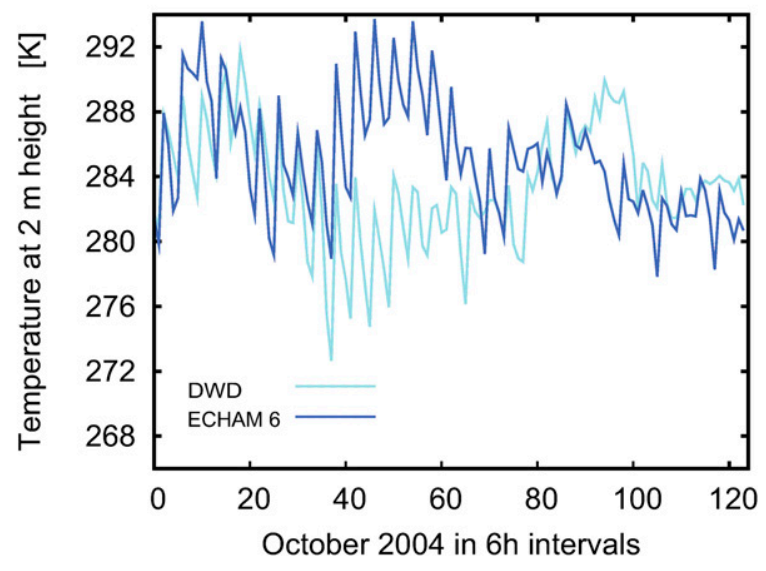

b)

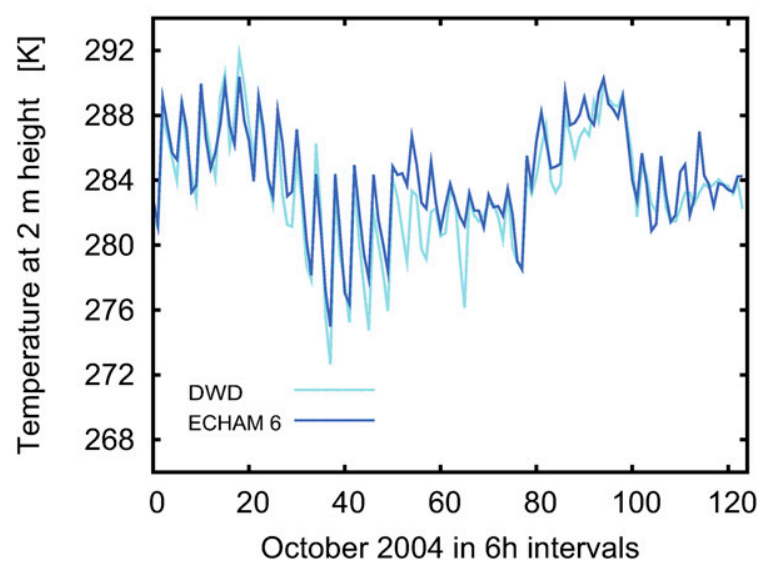

FIG. 11. Time series of 2-m temperature (K) in 6-h intervals for October 2004 at the Hamburg Airport for DWD data (light blue) and the nonnudged ECHAM6 simulation (dark blue). (b) As in (a), but with the dark blue curve showing the results of the ECHAM6 simulation using the plateau-shaped nudging profile for vorticity and divergence at $\mathrm{T} 30$ truncation $\left(\mathrm{T} 30 \_\mathrm{pl} \_\tau_{50 \_} d v\right.$ ).

term that describes the quality of two datasets in comparison to a reference dataset (Winterfeldt et al. 2011). Here, we compare nudged ECHAM6 data $(\Psi)$, NCEP-1 $\left(\Psi^{*}\right)$, and as reference DWD observation data $\left(\Psi_{0}\right)$. In contrast to tc, the BSS additionally describes the similarity between the considered datasets, as the amplitude of their variations is taken into account. A positive value of the BSS means that there is better agreement between ECHAM6 and the observation data than between NCEP-1 and the observation data. A negative value describes the opposite case. For BSS $=0$, both ECHAM6 and NCEP-1 show the same level of agreement with regard to the measured data. The experiment T30_pl_ $\tau_{50 \_} d v$, illustrated in Fig. 11b, has a BSS of -0.11 . In Fig. 11a the temporal evolution of the temperature, arising from 
TABLE 7. BSS and tc of the 2-m temperature (K) during October 2004 at the Hamburg Airport for various nudging time scales $x$ for the experiments T42_pa $\_\tau_{x \_} d v$ and T42_pl_$\tau_{x \_} d v$.

\begin{tabular}{lcccccc}
\hline \hline \multicolumn{1}{c}{$\tau_{5.5}$} & $\tau_{10}$ & $\tau_{50}$ & $\tau_{100}$ & $\tau_{500}$ & $\tau_{5000}$ \\
\hline T42_pa_$\tau_{x \_} d v$ & & & & & \\
BSS -0.23 & -0.27 & -0.12 & -0.21 & -0.76 & -0.86 \\
tc +0.89 & +0.88 & +0.90 & +0.89 & +0.61 & +0.46 \\
T42_pl_ $\tau_{x \_} d v$ & & & & & \\
BSS - & -0.22 & -0.21 & -0.04 & - & - \\
tc & - & +0.89 & +0.91 & +0.92 & - & - \\
\hline
\end{tabular}

the non-nudging experiment, shows, in some parts, an opposing trend. This fact is reflected clearly by a low tc of 0.21 and a BSS of -0.91 . Generally, the non-nudging simulation is of comparable quality as the well-known and frequently performed AMIP runs.

Table 7 presents the BSS and tc results for the 2-m temperature time series for various nudging time scales. Both BSS and tc have their maxima at a nudging time scale of $50 \mathrm{~min}$ for the parabolic nudging profile. However, for the plateau-shaped nudging profile, the BSS is higher for an $e$-folding time of $100 \mathrm{~min}$ although the tc shows its maximum at $50 \mathrm{~min}$. Table 8 shows the same quantities as Table 7, but for various truncations of the nudging wavenumber instead of the nudging time scale. Here, we can also deduce an optimal value for the truncation, which is the total wavenumber 30 . This also holds for the plateau profile.

The experiments with vertically constant nudging show the highest tc $(0.90)$ also for $10-\mathrm{m}$ wind at the Hamburg Airport station. Experiment T30_pl_ $\tau_{50 \_} d v$ shows slightly smaller correlations. Figure 12 a shows the temporal evolution of the wind speed of the nonnudging experiment. Similar to the 2-m temperature, little agreement with the observational data is found. This fact is reflected clearly by a low tc $=0.15$ and $\mathrm{BSS}=-0.82$. Figure $12 \mathrm{~b}$ displays the time series of $10-\mathrm{m}$ wind speed (W10M) of the spectrally nudged experiment T30_pl_ $\tau_{50 \_} d v$ and the observations. In contrast to $\mathrm{T} 2 \mathrm{M}$, the observational data for wind speed show stronger fluctuations and values around $11 \mathrm{~m} \mathrm{~s}^{-1}$. The fluctuations are smaller for the ECHAM6 simulation. In mountainous areas the smoothing of steep orography in the model leads to deficiencies in the simulation results because of different height levels compared to the observational data (not shown).

Tables 9 and 10 show the BSS and tc for W10M. For the parabolic nudging profile the optimum configuration shifts to shorter $e$-folding times and higher truncation wavenumbers. However, in the case of a plateau-shaped nudging profile, the optimal nudging time scale is still $50 \mathrm{~min}$ and a truncation wavenumber of 42 is optimal. Furthermore, the BSS for wind speed
TABLE 8. BSS and tc of the 2-m temperature $(\mathrm{K})$ during October 2004 at the Hamburg Airport for various nudging truncations $x$ in the experiments $T x \_$pa $\_\tau_{10} \_d v$ and $T x \_p l \_\tau_{10} d v$.

\begin{tabular}{|c|c|c|c|c|c|c|}
\hline & T62 & $\mathrm{T} 42$ & $\mathrm{~T} 30$ & $\mathrm{~T} 21$ & $\mathrm{~T} 11$ & T05 \\
\hline \multicolumn{7}{|c|}{ Tx_pa_$\tau_{10 \_} d v$} \\
\hline BSS & -0.27 & -0.27 & -0.08 & -0.45 & -0.72 & -0.9 \\
\hline tc & +0.84 & +0.88 & +0.90 & +0.84 & +0.67 & +0.0 \\
\hline \multicolumn{7}{|c|}{$\mathrm{T} x \_\mathrm{pl} \_\tau_{10 \_} d v$} \\
\hline BSS & -0.17 & -0.22 & -0.10 & -0.49 & - & -0.9 \\
\hline tc & +0.90 & +0.89 & +0.91 & +0.84 & 一 & +0.1 \\
\hline
\end{tabular}

is much higher for the plateau-shaped profile than for the parabolic example. In addition, there are no NCEP-1 reanalysis data for the highest ECHAM6 levels; therefore, at these levels no spectral nudging should be applied, which is the case in the plateau profile. Therefore, the results of this time series analysis suggest using the plateau-shaped nudging profile to gain the best results.

a)

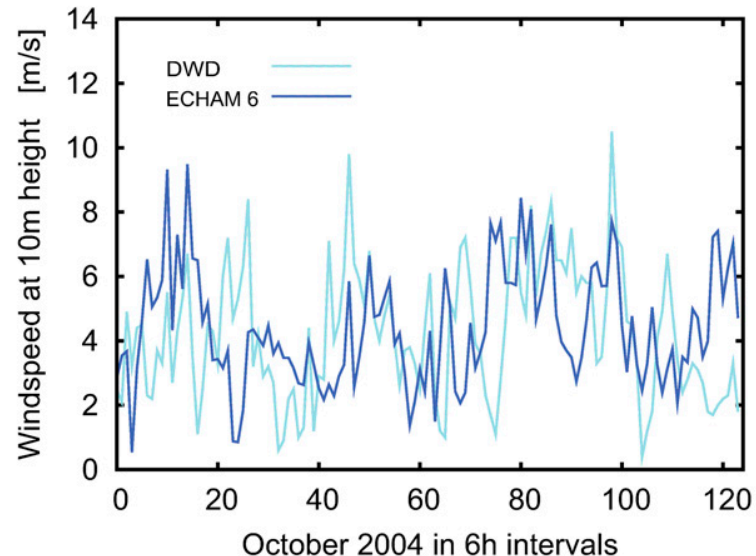

b)

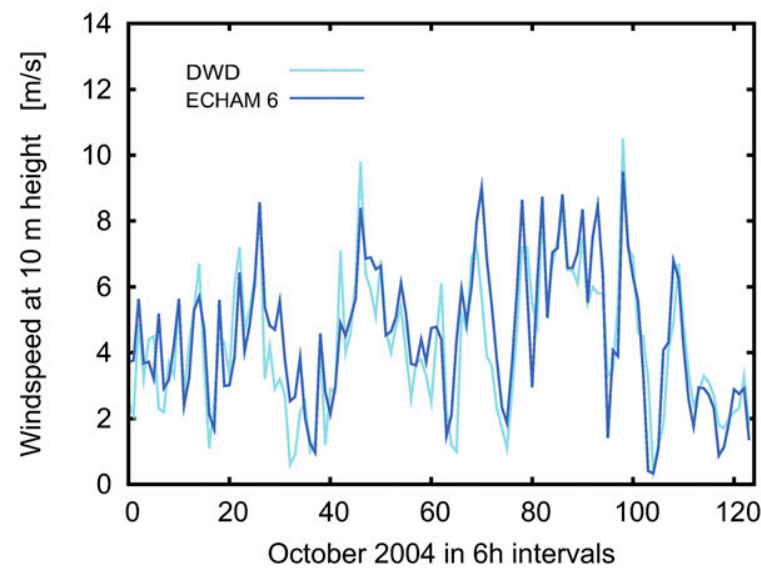

FIG. 12. As in Fig. 11, but for the 10-m wind $\left(\mathrm{m} \mathrm{s}^{-1}\right)$. 
TABLE 9. BSS and tc of the 10-m wind $\left(\mathrm{m} \mathrm{s}^{-1}\right)$ during October 2004 at the Hamburg Airport for various nudging time scales $x$ in the experiments T42_pa_ $\tau_{x \_} d v$ and T42_pl_ $\tau_{x \_} d v$.

\begin{tabular}{lcccccc}
\hline \hline & $\tau_{5.5}$ & $\tau_{10}$ & $\tau_{50}$ & $\tau_{100}$ & $\tau_{500}$ & $\tau_{5000}$ \\
\hline T42_pa_$\tau_{x \_} d v$ & & & & & \\
BSS -0.14 & -0.09 & -0.46 & -0.32 & -0.71 & -0.79 \\
tc +0.84 & +0.84 & +0.73 & +0.77 & +0.42 & +0.25 \\
T42_pl_ $\tau_{x \_} d v$ & & & & & \\
BSS - & -0.11 & -0.03 & -0.22 & - & - \\
tc & - & +0.84 & +0.86 & +0.83 & - & - \\
\hline
\end{tabular}

Large-scale and convective precipitation turns out to be a very sensitive quantity with regard to varying nudging configurations. Time series of daily precipitation sums for DWD observations and nudged ECHAM6 data showed higher tc's for plateau-shaped nudging profiles than for the parabolic form. Increasing the truncation wavenumbers ( $\geq \mathrm{T} 21)$ or decreasing the $e$-folding times $(\tau \leq 100 \mathrm{~min})$ leads to an increase in the tc from 0.41 to 0.87 . The higher the nudging strength, the stronger is the decrease in precipitation. The best agreement at Hamburg Airport between observations and nudged ECHAM6 data was found for the experiment T42_pl_ $\tau_{50 \_} d v$. Adding surface pressure to the nudging variables vorticity and divergence generally reduces the tc. Adding temperature to the wind in the nudging process may cause more issues because the phase change of water and onset of various microphysical processes will be influenced by a number of temperature and relative humidity thresholds (Zhang et al. 2014). Figure 13a shows the precipitation time series at Hamburg Airport for the nonnudging experiment while Fig. 13b displays the same for experiment T30_pl_ $\tau_{50 \_} d v$. Figure 13a indicates no correlation between the two time series in the case without nudging but Fig. 13b reveals that spectral nudging yields much better agreement. There, the tc amounts to 0.68 but the BSS is only -0.68 . The low BSS mainly results from the overestimation of the daily precipitation sum. NCEP-1 reveals too small precipitation values (see gray curve in Fig. 13b), presumably because of the coarse model resolution. It seems that the choice of wavenumber and $e$-folding time in the nudging process plays an important role in achieving more realistic precipitation amounts. Generally, relatively weak nudging strength is recommended for RCMs (Shan et al. 2012) to obtain a better spatial and temporal distribution of precipitation and to avoid the suppression of extreme precipitation events. We think that shorter $e$-folding times are necessary for GCMs to achieve results similar to those from RCMs because of the lack of lateral boundary control.

For global precipitation fields, NCEP-1 displays smooth structures in the precipitation regions while ECHAM6 is capable of reproducing small-scale features
TABLE 10. BSS and tc of the $10-\mathrm{m}$ wind $\left(\mathrm{m} \mathrm{s}^{-1}\right)$ during October 2004 at the Hamburg Airport for various nudging truncations $x$ in the experiments $\mathrm{T} x \_\mathrm{pa} \_\tau_{10 \_} d v$ and $\mathrm{T} x \_\mathrm{pl} \_\tau_{10 \_} d v$.

\begin{tabular}{|c|c|c|c|c|c|c|}
\hline & $\mathrm{T} 62$ & $\mathrm{~T} 42$ & T30 & $\mathrm{T} 21$ & $\mathrm{~T} 11$ & T05 \\
\hline \multicolumn{7}{|c|}{ Tx_pa_$\tau_{10 \_} d v$} \\
\hline BSS & -0.12 & -0.09 & -0.12 & -0.20 & -0.80 & -0.86 \\
\hline tc & +0.84 & +0.84 & +0.83 & +0.82 & +0.07 & +0.06 \\
\hline \multicolumn{7}{|c|}{$T x \_p l \_\tau_{10} \_d v$} \\
\hline BSS & +0.08 & -0.11 & -0.23 & -0.37 & - & -0.83 \\
\hline tc & +0.85 & +0.84 & +0.82 & +0.78 & - & +0.06 \\
\hline
\end{tabular}

such as frontal rainbands or tropical storms (not shown). A comparison with ERA-Interim shows closer agreement with ECHAM6 than with NCEP-1 for the precipitation patterns, but the precipitation peak values are larger in ECHAM6 than in ERA-Interim. Figure 14 displays the global time correlation field between

a)

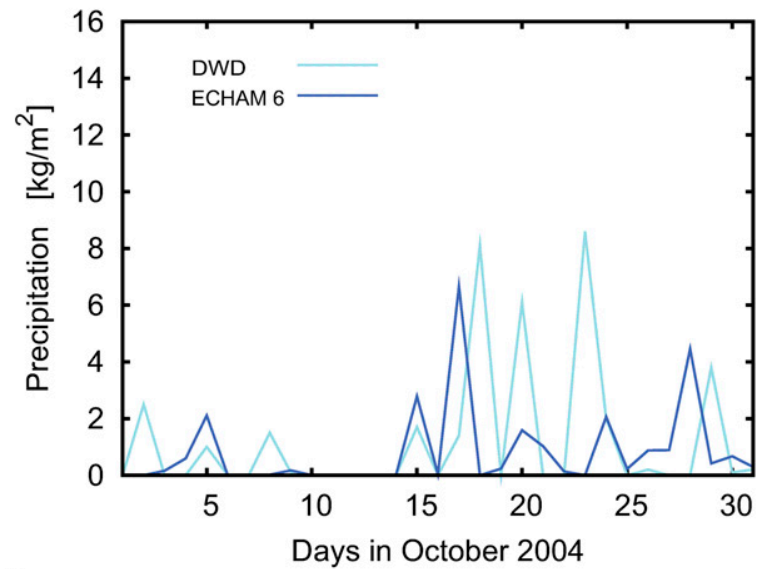

b)

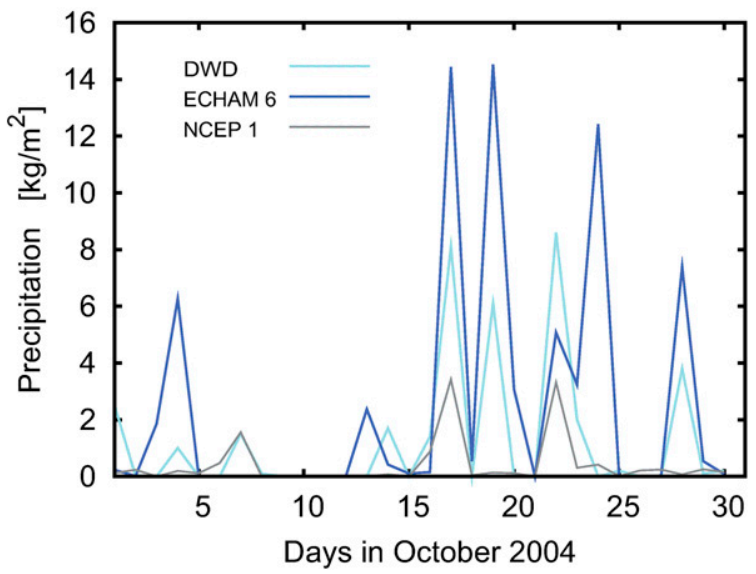

FIG. 13. As in Fig. 11, but for total precipitation $\left(\mathrm{kg} \mathrm{m}^{-2}\right)$ in daily intervals. For comparison, the NCEP-1 time series (gray) was added. 


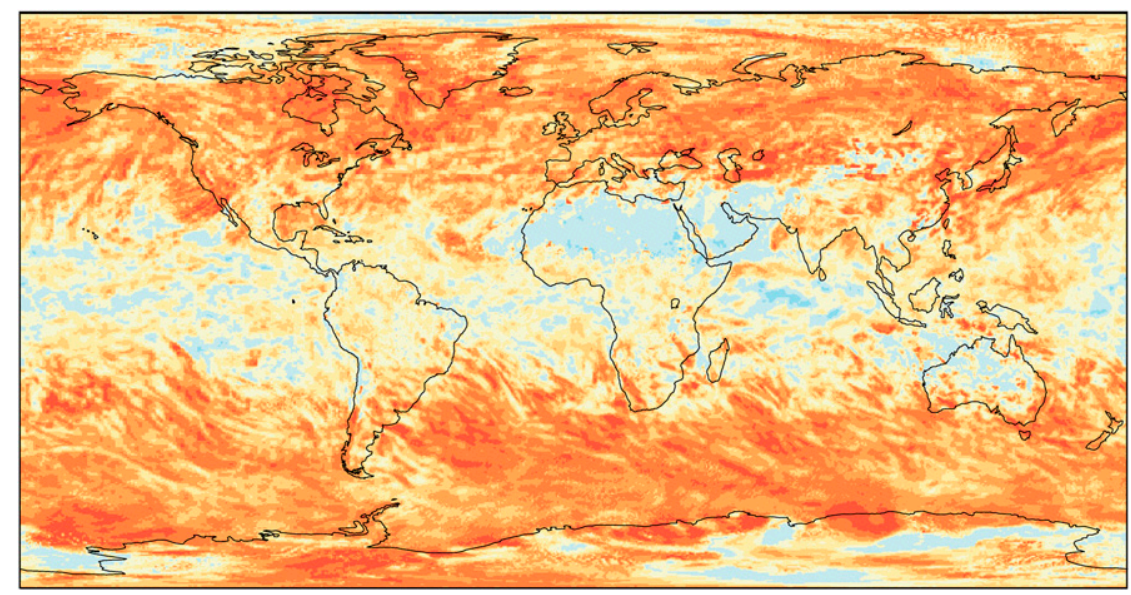

Precipitation correlation

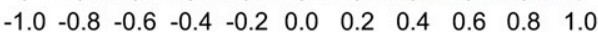

FIG. 14. Global time correlation of 6-hourly precipitation sums $\left(\mathrm{kg} \mathrm{m}^{-2}\right)$ during October 2004 between ECHAM6 with the nudging configuration T30_pl_ $\tau_{50 \_} d v$ and ERA-Interim.

experiment T30_pl_ $\tau_{50 \_} d v$ and ERA-Interim for the 6-hourly precipitation sums in October 2004. A high correlation of up to $90 \%$ can be observed in the extratropical region. However, the precipitation correlation becomes negative in some tropical regions.

\section{h. Evaluation of Typhoon Tokage}

In this section the structure, strength, and position of Typhoon Tokage were studied dependent on different nudging configurations in ECHAM6. Based on the besttrack data provided by the Japan Meteorological Agency, the typhoon appeared on 10 October 2004 and lasted until 23 October. After the beginning as a tropical depression near Mariana Islands $\left(14.9^{\circ} \mathrm{N}, 145.1^{\circ} \mathrm{E}\right)$, it underwent a rapid deepening 3 days later. On 17 October, Tokage reached its strongest phase before the storm hit Japan on 20 October. The typhoon caused large damage on land before it transformed into an extratropical cyclone. Figure 15a shows the NCEP-1 vorticity field at the lowest model level on 18 October. For a coarse spatial resolution such as the one used in the reanalysis, tropical cyclones are often characterized by weaker vorticity, weaker wind speed values, and higher central pressures in comparison to the observations. Tokage showed a nearly circular structure with highest vorticity values of $2.4 \times$ $10^{-4} \mathrm{~s}^{-1}$ in NCEP-1 on 19 October 2004 (Fig. 15a). However, best-track data locate the minimum surface pressure of $940 \mathrm{hPa}$ on 17 October. NCEP-1 has a minimum of $984 \mathrm{hPa} 2$ days later and the center location of the storm coincides well with the observations $\left(29.1^{\circ} \mathrm{N}, 129.4^{\circ} \mathrm{E}\right)$.

The number of detected cyclones and their temporal developments of wind speed and core pressure in the
ECHAM simulations were evaluated by applying a tracking algorithm in order to analyze how well the various nudging configurations lead to a realistic model representation of meteorological phenomena at all scales. The most realistic simulation in ECHAM6 for this intense storm was achieved when using a truncation at total wavenumber 30 , an $e$-folding time of $50 \mathrm{~min}$, and a plateau-shaped vertical profile (T30_pl_ $\tau_{50 \_} d v$; Fig. 15b). Even though the observed SLP values are never reached in ECHAM (minimum $966 \mathrm{hPa}$ ) and there is a time lag as in NCEP-1, the new hindcast adds value in comparison to its forcing reanalysis data.

\section{Summary, discussion, and conclusions}

In this sensitivity study, we have investigated the dependence of simulated global atmospheric fields on spectral nudging by modifying its configuration in the global circulation model ECHAM6 (T255L95). For dynamical downscaling, the spectral nudging method was applied to nudge global model fields toward the corresponding large-scale fields from the NCEP-1 reanalysis data. It is one of the first studies to apply and systematically evaluate the spectral nudging in a global model and the first to use various height profiles and selective nudging of different wavenumbers both in the zonal and meridional directions. The aim was to find the most suitable nudging configuration at a high spatiotemporal resolution by using various truncation options, height profiles for the nudging coefficient, $e$-folding times, and choices of nudging variables. The evaluation is based on comparison of high-resolution ECHAM6 
a)

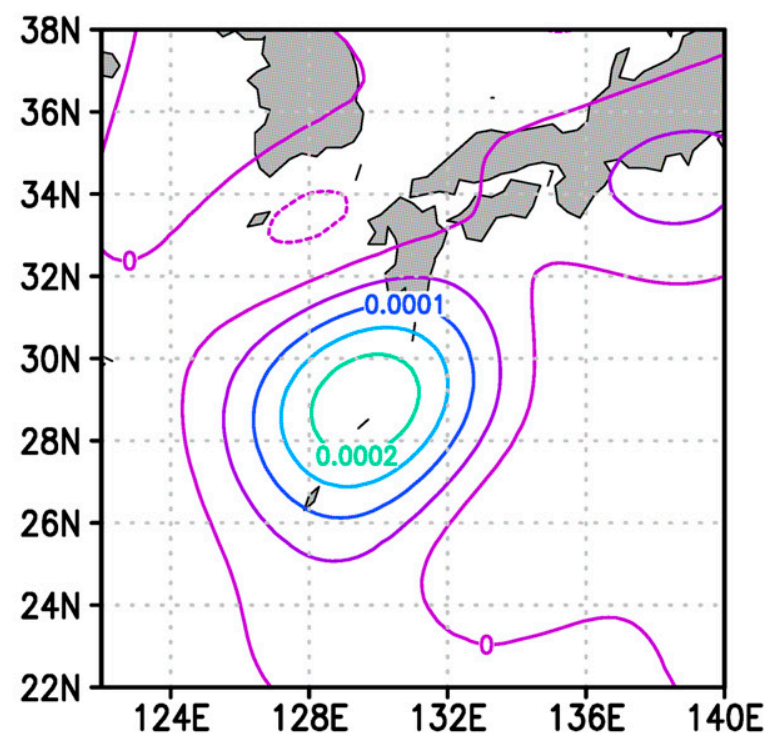

b)

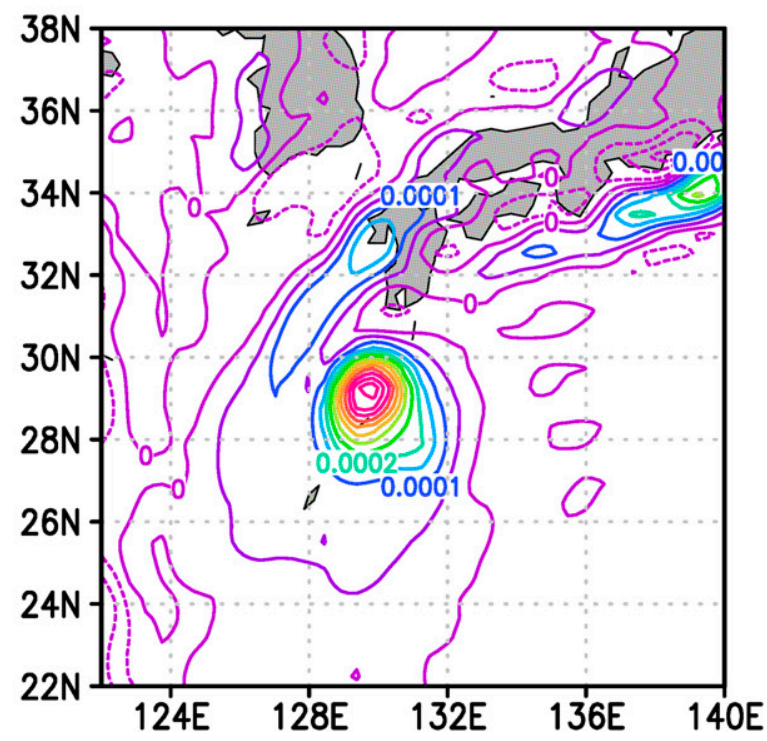

FIG. 15. Vorticity fields (contour interval is $0.5 \times 10^{-4} \mathrm{~s}^{-1}$ ) for Typhoon Tokage at maximum strength in NCEP-1 at 1800 UTC 19 Oct 2004 for (a) NCEP-1 and (b) ECHAM6 spectrally nudged with the plateau profile (T30_pl_ $\tau_{50 \_} d v$ ).

results with observational station data and reanalysis data using various statistical measures, namely correlation in wavenumber space, similarity, Brier skill score (BSS), time correlation (tc), and RMSE.

We demonstrated that spectral nudging of ECHAM6 works efficiently by successfully reducing global differences in 2-m height temperature in the NCEP-1 dataset in comparison to ECHAM6 without nudging. The effectiveness of the application of spectral nudging was shown in a wavenumber spectrum, which displays a visible high correlation between the NCEP-1 forcing data and the nudged ECHAM6 data with regard to the 500 -hPa vorticity field. The shape of the vertical nudging profile also proved to be important for the properties of the reconstructed dataset. The parabolic nudging height profile shows higher similarity profiles both for large and small scales than are found for the plateau-shaped case. The height-independent nudging profile, prescribed by the ECHAM6 configuration used by Jeuken et al. (1996), delivers the highest values of the large-scale similarity $P_{g}$ in the boundary layer. But high values of the regional-scale similarity $P_{r}$ indicate that the generation of small-scale processes may be inhibited as a result of the very strong nudging control exerted on the GCM. The energy spectrum between nudged ECHAM6 and NCEP-1 coincides particularly well for the nudged wavenumbers and shows merely weak dependence on the choice of truncation wavenumbers and $e$-folding times. The highest BSS for the 2-m height temperature at the Hamburg Airport station was achieved with a configuration that used an $e$-folding time of $50 \mathrm{~min}$ and a truncation at total wavenumber 30 for the parabolic and plateau-shaped profiles. Analyzing the 2-m temperature fields at the large spatial scales yields a high time correlation with ERA-Interim. At the regional scale the spectrally nudged ECHAM6 reproduces reasonably well the corresponding spatial pattern of ERA-Interim on certain dates, but without nudging, the patterns deviate largely since the hindcast skill of the AMIPtype simulation is limited. This indicates that at the regional scale spectral nudging is required for a usable reconstruction.

Evaluation of zonally averaged profiles for $850-\mathrm{hPa}$ temperature and $200-\mathrm{hPa}$ wind speed divided into three latitudinal zones (tropical and extratropical zones in the Northern and Southern Hemispheres) showed high time correlation values and small RMSEs in comparison to the ERA-Interim reanalysis only for the extratropical regions. Further analysis is needed to assess the reasons for the low correlations in the tropics. Nevertheless, a good representation of tropical cyclones like Typhoon Tokage is achieved with the plateau-shaped nudging profile and a time scale of $50 \mathrm{~min}$.

In summary, we found that the best results are obtained by a spectral nudging configuration, including a truncation at total wavenumber 30 , an $e$-folding time of $50 \mathrm{~min}$, nudging of the variables vorticity, and divergence combined with a plateau-shaped nudging profile. This time scale is only about half the value 
suggested to be optimal for an RCM with a parabolic nudging height profile (von Storch et al. 2000). Therefore, we conclude that in global models a stronger spectral nudging than in RCMs should be applied, presumably because they lack the lateral sponge zones that offer additional adaptability to the driving dataset and thus considerable control of the forcing data. We performed a long-term ECHAM6 simulation at a resolution of T255 for the last $67 \mathrm{yr}$ using the heredetermined nudging configuration. ${ }^{1}$ With this hindcast simulation, computed with an unchanged model system over time, we try to achieve realistic weather phenomena at most spatial and temporal scales in order to study their long-term changes. So far, we have concentrated on short time scales because of the computation time constraint. It would be very interesting to analyze the effects of spectral nudging on meteorological circulations of various spatial scales like monsoons, ENSO, or the NAO. It would also be tempting to apply the spectral nudging technique in a global coupled atmosphereocean model to see its impact on the ocean circulation. Indeed, Herrmann and Somot (2008) found a high impact of spectral nudging in open-ocean convection driven by a spectrally nudged regional atmospheric model. The spectral resolution of T255 is still too small to resolve intense mesoscale vortices like tropical cyclones (Bengtsson et al. 2007). Therefore, additional benefit from the global spectral nudging might arise when the model is run at an even higher resolution, which should be feasible in the future. Finally, we would like to emphasize that the spectrally nudged hindcast that was presented in this study, took only about $10 \%$ more computation time than the AMIP-type setup and, therefore, to achieve realistic simulations of the past decades, we recommend using this configuration.

Acknowledgments. Work was supported through the Cluster of Excellence "CliSAP" (EXC177), Universität Hamburg, funded through the German Research Foundation (DFG). This work is a contribution to the "Helmholtz Climate Initiative REKLIM" (Regional Climate Change), a joint research project of the Helmholtz Association of German Research Centres (HGF). The German Climate Computing Center (DKRZ) provided the computer hardware for the ECHAM6 simulation in the project global high-resolution climate reconstructions,

\footnotetext{
${ }^{1}$ The whole hourly ECHAM6 dataset from 1948 to 2015 with more than 200 meteorological variables is now available online from the German Climate Computing Center (http://cera-www. dkrz.de/WDCC/ui/Compact.jsp?acronym =CLISAP_MPI-ESMXR_t255195).
}

which were funded by the Federal Ministry of Education and Research (BMBF). The NCEP-1-NCAR reanalysis data were provided by NCAR. The authors are grateful to ECMWF for providing the ERA-Interim reanalysis and also thank the DKRZ service for their helpful support in all technical issues related to ECHAM6. We thank Eduardo Zorita for his helpful comments and suggestions. We thank Beate Gardeike and Ingeborg Nöhren for assistance in producing the high quality graphics. We thank the two anonymous reviewers for their constructive comments, which helped to improve the manuscript.

\section{REFERENCES}

Alexandru, A., R. De Elia, R. Laprise, L. Separovic, and S. Biner, 2009: Sensitivity study of regional climate model simulations to large-scale nudging parameters. Mon. Wea. Rev., 137, 16661686, doi:10.1175/2008MWR2620.1.

Bauer, H.-S., 2000: Validation of clouds in the ECHAM 4 model using a dynamical adjustment technique. Ph.D. thesis, MaxPlanck-Institut für Meteorologie, $143 \mathrm{pp}$.

—_, V. Wulfmeyer, and L. Bengtsson, 2008: The representation of a synoptic-scale weather system in a thermodynamically adjusted version of the ECHAM4 general circulation model. Meteor. Atmos. Phys., 99, 129-153, doi:10.1007/s00703-007-0275-2.

Bengtsson, L., K. I. Hodges, M. Esch, N. Keenlyside, L. Kornblueh, J. J. Luo, and T. Yamagata, 2007: How may tropical cyclones change in a warmer climate? Tellus, $\mathbf{5 9 A}$, 539-561, doi:10.1111/j.1600-0870.2007.00251.x.

Dee, D., and Coauthors, 2011: The ERA-Interim reanalysis: Configuration and performance of the data assimilation system. Quart. J. Roy. Meteor. Soc., 137, 553-597, doi:10.1002/ qj. 828 .

Eden, J. M., M. Widmann, D. Grawe, and S. Rast, 2012: Skill, correction, and downscaling of GCM-simulated precipitation. J. Climate, 25, 3970-3984, doi:10.1175/JCLI-D-11-00254.1.

Feser, F., 2006: Enhanced detectability of added value in limitedarea model results separated into different spatial scales. Mon. Wea. Rev., 134, 2180-2190, doi:10.1175/MWR3183.1.

Gates, W. L., 1992: AMIP: The Atmospheric Model Intercomparison Project. Bull. Amer. Meteor. Soc., 73, 1962-1970, doi:10.1175/1520-0477(1992)073<1962:ATAMIP>2.0.CO;2.

Giorgetta, M. A., and Coauthors, 2013a: Climate and carbon cycle changes from 1850 to 2100 in MPI-ESM simulations for the Coupled Model Intercomparison Project phase 5. J. Adv. Model. Earth Syst., 5, 572-597, doi:10.1002/jame.20038.

— , and Coauthors, 2013b: The atmospheric general circulation model ECHAM6: Model description. Reports on Earth System Science, Max Planck Institute for Meteorology, Hamburg, Germany, 172 pp.

Herrmann, M. J., and S. Somot, 2008: Relevance of ERA40 dynamical downscaling for modeling deep convection in the Mediterranean Sea. Geophys. Res. Lett., 35, L04607, doi:10.1029/2007GL032442.

Jacob, D., and R. Podzun, 1997: Sensitivity studies with the regional climate model REMO. Meteor. Atmos. Phys., 63, 119129, doi:10.1007/BF01025368.

Jeuken, A. B. M., P. C. Siegmund, L. C. Heijboer, J. Feichter, and L. Bengtsson, 1996: On the potential of assimilating meteorological 
analyses in a global climate model for the purpose of model validation. J. Geophys. Res., 101, 16 939-16950, doi:10.1029/ 96JD01218.

Kaas, E., and Coauthors, 2000: Project on tendency evaluations using new techniques to improve atmospheric long-term simulations. EU Commission POTENTIALS Final Rep., 93 pp.

Kalnay, E., and Coauthors, 1996: The NCEP/NCAR 40-Year Reanalysis Project. Bull. Amer. Meteor. Soc., 77, 437-471, doi:10.1175/1520-0477(1996)077<0437:TNYRP>2.0.CO;2.

Kim, J.-E., and S.-Y. Hong, 2012: A global atmospheric analysis dataset downscaled from the NCEP-DOE reanalysis. J. Climate, 25, 2527-2534, doi:10.1175/JCLI-D-11-00534.1.

Liu, P., A. Tsimpidi, Y. Hu, B. Stone, A. Russell, and A. Nenes, 2012: Differences between downscaling with spectral and grid nudging using WRF. Atmos. Chem. Phys., 12, 3601-3610, doi:10.5194/acp-12-3601-2012.

Matthias, V., T. Shepherd, P. Hoffmann, and M. Rapp, 2015: The Hiccup: A dynamical coupling process during the autumn transition in the Northern Hemisphere-Similarities and differences to sudden stratospheric warmings. Ann. Geophys., 33, 199-206, doi:10.5194/angeo-33-199-2015.

Miguez-Macho, G., G. L. Stenchikov, and A. Robock, 2004: Spectral nudging to eliminate the effects of domain position and geometry in regional climate model simulations. J. Geophys. Res., 109, D13104, doi:10.1029/2003JD004495.

- _ _ and 2005: Regional climate simulations over North America: Interaction of local processes with improved large-scale flow. J. Climate, 18, 1227-1246, doi:10.1175/ JCLI3369.1.

Nozawa, T., and S. Yoden, 1997: Spectral anisotropy in forced twodimensional turbulence on a rotating sphere. Phys. Fluids, 9 , 3834-3842, doi:10.1063/1.869518.

Omrani, H., P. Drobinski, and T. Dubos, 2012: Spectral nudging in regional climate modelling: How strongly should we nudge? Quart. J. Roy. Meteor. Soc., 138, 1808-1813, doi:10.1002/ qj.1894.

Radu, R., M. Déqué, and S. Somot, 2008: Spectral nudging in a spectral regional climate model. Tellus, 60A, 898-910, doi:10.1111/j.1600-0870.2008.00341.x.

Riette, S., and D. Caya, 2002: Sensitivity of short simulations to the various parameters in the new CRCM spectral nudging. Research Activities in Atmospheric and Oceanic Modelling, H. Ritchie, Ed., WMO/TD-1105, 7.39-7.40. [Available online at http://www.wcrp-climate.org/WGNE/BlueBook/ 2002/individual-articles/07_s_bastien_riette.pdf.]
Rockel, B., C. L. Castro, R. A. Pielke, H. von Storch, and G. Leoncini, 2008: Dynamical downscaling: Assessment of model system dependent retained and added variability for two different regional climate models. J. Geophys. Res., 113, D21107, doi:10.1029/2007JD009461.

Scinocca, J. F., and Coauthors, 2016: Coordinated global and regional climate modeling. J. Climate, 29, 17-35, doi:10.1175/ JCLI-D-15-0161.1.

Shan, H., Y. Guan, and J. Huang, 2012: Effects of spectral nudging on the 2010 East Asia summer monsoon using WRF model. Chin. J. Oceanol. Limnol., 30, 1105-1115, doi:10.1007/ s00343-012-1272-y.

Steppeler, J., G. Doms, U. Schättler, H. W. Bitzer, A. Gassmann, U. Damrath, and G. Gregoric, 2003: Meso-gamma scale forecasts using the nonhydrostatic model LM. Meteor. Atmos. Phys., 82, 75-96, doi:10.1007/s00703-001-0592-9.

Timmreck, C., and M. Schulz, 2004: Significant dust simulation differences in nudged and climatological operation mode of the AGCM ECHAM. J. Geophys. Res., 109, D13202, doi:10.1029/2003JD004381.

von Storch, H., H. Langenberg, and F. Feser, 2000: A spectral nudging technique for dynamical downscaling purposes. Mon. Wea. Rev., 128, 3664-3673, doi:10.1175/1520-0493(2000)128<3664: ASNTFD $>2.0 . \mathrm{CO} ; 2$.

Waldron, K. M., J. Paegle, and J. D. Horel, 1996: Sensitivity of a spectrally filtered and nudged limited-area model to outer model options. Mon. Wea. Rev., 124, 529-547, doi:10.1175/ 1520-0493(1996)124<0529:SOASFA > 2.0.CO;2.

Weisse, R., and F. Feser, 2003: Evaluation of a method to reduce uncertainty in wind hindcasts performed with regional atmosphere models. Coastal Eng., 48, 211-225, doi:10.1016/ S0378-3839(03)00027-9.

Winterfeldt, J., B. Geyer, and R. Weisse, 2011: Using QuikSCAT in the added value assessment of dynamically downscaled wind speed. Int. J. Climatol., 31, 1028-1039, doi:10.1002/joc.2105.

Yoshimura, K., and M. Kanamitsu, 2008: Dynamical global downscaling of global reanalysis. Mon. Wea. Rev., 136, 2983 2998, doi:10.1175/2008MWR2281.1.

Zahn, M., H. von Storch, and S. Bakan, 2008: Climate mode simulation of North Atlantic polar lows in a limited area model. Tellus, 60A, 620-631, doi:10.1111/ j.1600-0870.2008.00330.x.

Zhang, K., and Coauthors, 2014: On the use of nudging for aerosolclimate model intercomparison studies. Atmos. Chem. Phys., 14, 8631-8645, doi:10.5194/acp-14-8631-2014. 